\title{
Testing for the rationality of central bank interest rate forecasts
}

\author{
Michael Frenkel ${ }^{1} \cdot$ Jin-Kyu Jung ${ }^{1}$ (D) Jan-Christoph Rülke ${ }^{2}$
}

Received: 20 January 2020 / Accepted: 16 March 2021 / Published online: 8 May 2021

(c) The Author(s) 2021

\begin{abstract}
In this paper, we study the bias in interest rate projections of five central banks, namely the central banks of the Czech Republic, New Zealand, Norway, Sweden, and the USA. We examine whether central bank projections are based on an asymmetric loss function and report evidence that central banks perceive an overprojection of their longer-term interest rate forecasts as twice as costly as an underprojection of the same size. We find that forecast rationality is consistent with biased interest rate projections under the assumption of an asymmetric loss function, which contributes to explaining the behavior of the examined central banks and their forecasts.
\end{abstract}

Keywords Asymmetric loss · Forecast rationality $\cdot$ Interest rate forecasts

JEL Classification E43 $\cdot$ E47 $\cdot$ E58

\section{Introduction}

Over the past 20 years, central banks have increasingly embarked on a stance of more transparent policy-making and more open central bank communication. While tra-

Contents of this paper were included in an unpublished doctoral dissertation entitled On Recent Advances in Economic Forecasting Topics which was handed in on 18 March 2019 and accepted on 14 June 2019 at WHU - Otto Beisheim School of Management in Vallendar, Germany.

$凶 \quad$ Jin-Kyu Jung

jin-kyu.jung@whu.edu

Michael Frenkel

michael.frenkel@whu.edu

Jan-Christoph Rülke

jan-christoph.ruelke@ebs.edu

1 WHU - Otto Beisheim School of Management, Vallendar, Germany

2 EBS - Universität für Wirtschaft und Recht, Wiesbaden, Germany 
ditional views on central bank communication advocated the publication of as little specific information as possible, the acknowledgement of the role that public expectations play in macroeconomic stabilization has brought about a shift toward more openness in communicating policy intentions and decisions (Rudebusch and Williams 2008). Against this background, central banks have recently introduced a number of innovative, new instruments as part of their efforts to guide and lead financial market expectations into the desired direction.

One of the latest innovations in this context and one considered to be a "new frontier" in central bank communication is the publication of interest rate projections (Blinder et al 2008). The publication of such forecasts was first introduced by the Reserve Bank of New Zealand in 1997, when it issued a forecast of the future 90-day bank bill rate as part of its Monetary Policy Statements aiming at providing some strong guidance for interest rate expectations. Since then, a few other central banks followed this approach. In 2005, the Norges Bank began to issue projections of its own key policy rate. In 2007, the Swedish Riksbank began to publish forecasts of the future repo rate and the CNB followed in 2008 with forecasts of the Prague Interbank Offered Rate (PRIBOR). Iceland's Sedlabanki Islands published projections of its own policy rate starting in 2006, but discontinued this policy in 2010. In 2012, the US Federal Reserve System started publishing forecasts of its target federal funds rate, which can also be interpreted as increased interest in this means of central bank communication. Even though only a handful of central banks have so far published projected interest rate paths, by now enough data have accumulated for empirical research, making this a "high-priority area" for academic research in general (Blinder et al 2008).

In the context of this innovative approach to more transparent central bank communication, the academic literature on interest rate projections of central banks is still in a nascent stage. Rudebusch and Williams (2008) and Gosselin et al (2008) discuss the value of publishing interest rate projections. More specifically, Rudebusch and Williams (2008) find that "communication of interest rate projections can better align the public's and the central bank's expectations" and that this improved "alignment of expectations generally leads to improvements in macroeconomic performance." However, they point out that a misinterpretation by the public of such interest rate forecasts as "unconditional commitments" might present a significant pitfall to this instrument of central bank communication. Gosselin et al (2008) use this reasoning and formulate conditions under which central bank transparency leads to welfare losses: assuming a significant degree of information heterogeneity between a central bank and the public, this communication policy should not be pursued if the central bank shows signs of time inconsistency. Detmers and Nautz (2014) find that interest rate projections do appear to be helpful in the overall market expectations management of a central bank, but, at the same time, such projections tend to become stale quickly, which then contributes to increasing market uncertainty. They also show that interest rate projection horizons beyond four quarters do not provide much useful information to markets and might even lead to higher interest rate volatility (Detmers and Nautz 2013).

Building upon the existing literature, this paper aims at contributing to the investigation of interest rate projections as a new means of central bank communication. More specifically, the paper compares these projections with actual outcomes and examines what kind of loss function the interest rate forecasts are possibly based on. 
In this context, we are interested in identifying whether central banks' interest rate projections truly follow a symmetric loss function and can therefore be assumed to be unbiased.

Our study focuses on the interest rate projections of the central banks of the Czech Republic, New Zealand, Norway, and Sweden. These central banks have published such projections for at least the past decade within their inflation-targeting framework. In addition, we also take the interest rate projections of the US Federal Reserve into account, albeit they are subject to a slightly different structure, because they provide the individual opinions on the appropriate future federal funds rate of all Federal Open Market Committee (FOMC) members rather than an aggregated point forecast. We examine the forecast errors (i.e., the difference between the realized interest rate and the interest rate forecast) across different forecast horizons and make use of an approach developed by Elliott et al (2005) to determine whether these forecast errors follow a symmetric or an asymmetric loss function. From a theoretical perspective, a number of reasons might warrant central banks to over- or underestimate future policy rates, e.g., to secure greater leeway for the effects of counter-inflationary or counter-deflationary policies in times of need.

More generally, the analysis of macroeconomic projections has gained considerable attention in recent years. Studies have typically focused on projections published by financial market participants (Dovern 2015), international organizations (Frenkel et al 2013), or macroeconomic models (Wieland and Wolters 2011). Our analysis of interest rate projections by central banks is relevant for several reasons. First, financial market participants closely follow the general communication of central banks to form expectations about future interest rate decisions (Neuenkirch 2012). If central banks provide fairly accurate interest rate forecasts, financial market participants may use such forecasts in forming their expectations rather than trying to infer future developments from the verbal and, thus, more qualitative communication. The analysis is also interesting from an economic policy maker's point of view due to the fiscal-monetary policy interaction (Davig et al 2011). Hence, fiscal policy should be aware of the future interest rate path, which is reflected in central bank's interest rate projections. If central banks do not bind themselves to their projections, the effects of fiscal policy become more uncertain. Finally, the analysis of interest rate projections might be useful, because households and firms make bad consumption-savings decisions when monetary policy is unanticipated (Leeper et al 2011). In this regard, our paper contributes to the discussion about monetary foresight and forward guidance of monetary policy (Pierdzioch and Rülke 2014).

To the best of our knowledge, our study is the first one that compares interest rate projections of central banks and their actual outcomes. Although there are a number of studies that investigate the issue of rules versus discretion and the central bank's desire to improve monetary foresight, research has not yet provided empirical evidence of the underlying loss function of central banks' interest rate projections. To this end, our study applies the concept of an asymmetric loss function which has been used in other studies to, for example, investigate forecasts of oil prices (Pierdzioch et al 2015), exchange rates (Fritsche et al 2015), and other macroeconomic variables (Frenkel et al 2012). 
Table 1 Details on observation periods, frequencies, forecast horizons, and observation periods. Source: Česká Národní Banka, Norges Bank, Reserve Bank of New Zealand, Sveriges Riksbank, US Federal Reserve. The available forecast horizons for New Zealand, Norway, and Sweden differ across time, and only forecast data for up to 24 months have been used in order to guarantee a consistent dataset

\begin{tabular}{lllll}
\hline Country & Period & Frequency & Forecast horizon & Obs. periods \\
\hline Czech Republic & 2008 Q1-2018 Q4 & Quarterly & $3-18$ months & 44 \\
New Zealand & 1997 Q4-2018 Q4 & Quarterly & $3-24$ months & 85 \\
Norway & 2005 Q1-2018 Q4 & Triannually & $3-24$ months & 46 \\
Sweden & 2007 Q1-2018 Q4 & Quarterly & $3-24$ months & 50 \\
USA & 2012 Q1-2018 Q3 & Biannually & $1-2$ years & 14 \\
\hline
\end{tabular}

†The interest rate forecasts for the USA pertain to end of the current year, end of next year, in two years, and in the "longer run" as described in Sect. 2.5

The remainder of this paper is organized as follows: Sect. 2 gives an overview of the interest rate projection data of the central banks of the Czech Republic, New Zealand, Norway, Sweden, and the USA. Section 3 discusses some stylized facts of the projections. Section 4 lays out the econometric model that allows us to estimate the loss function of a central bank. Section 5 presents the results of our analysis. Section 6 presents some robustness tests for our findings, and Sect. 7 offers some conclusions.

\section{The data set}

We study the interest rate projections of the central banks of the Czech Republic, New Zealand, Norway, and Sweden, all of which have been publishing such projections for at least the past decade within their inflation-targeting framework. We also examine interest rate projections of the US Federal Reserve, albeit these are subject to a slightly different structure. More specifically, they comprise the individual opinions for the appropriate future federal funds rate of all FOMC members, but they do not issue an aggregated point forecast. The analyses in Sects. 4 to 6 consider a total of more than 2200 interest rate forecasts across different forecast horizons and observations. As the publication of interest rate forecasts of the different central banks started in different years, the observation periods vary in both length and forecast horizons. Table 1 summarizes the observational details of each of the five central banks.

\subsection{New Zealand}

The Reserve Bank of New Zealand (RBNZ) was the first central bank that published interest rate projections. It first published interest rate projections in the last quarter of 1997 and has been publishing these every quarter for forecast horizons between 1 month and 36 months ever since. The RBNZ has long been known for pioneering new, innovative instruments in monetary policy, and central bank communication. For instance, the concept of inflation targeting and the two percent inflation rate target both originated in New Zealand in 1989 long before this became best practice in monetary 
policy for many central banks across the globe (Archer 2005). The RBNZ initially released forecasts for the 90-day bank bill rate starting in its June 1997 Monetary Policy Statement edition. However, only as of December 2000, the RBNZ consistently published projections with a forecast horizon of at least 12 months. The projected 90day bank bill rate is a wholesale interbank rate within New Zealand, i.e., a market reference interest rate.

\subsection{Norway}

In contrast to the RBNZ, the Norges Bank's interest rate projections do not refer to a wholesale interbank rate, but to its own key interest rate, i.e., an interest rate that the central bank directly determines. This represents the interest rate paid on overnight bank deposits ${ }^{1}$ with the Norwegian central bank and is therefore a monetary policy instrument that the Norges Bank directly influences. The first forecasts were published in late 2005 as part of the last Monetary Policy Statement of that year. The Norges Bank published 3 Monetary Policy Reports per year with forecasts in the same format until the end of 2012. In 2013, it increased the publication frequency to 4 times per year.

\subsection{Sweden}

Similar to the projections in Norway, the Swedish Riksbank has published forecasts of its own repo rate. The Swedish repo rate is the interest rate at which commercial banks can borrow or deposit money for a period of 7 days with the central bank. Even though the Swedish Riksbank has long included forward rate implied projections of the repo rate in its inflation reports, it has only published an actual repo rate forecast in its Monetary Policy Reports since February 2007.

\subsection{Czech Republic}

The publication of interest rate projections of the Czech National Bank (CNB) began in 2008. Projections have been on a quarterly basis and have referred to the 3-month PRIBOR, which is a wholesale interbank rate in the Czech Republic. The CNB's projections therefore refer to an interest rate that the central bank can only influence indirectly (as opposed to, e.g., the key interest rate that is directly set by the central bank). When examining these PRIBOR projections, we thus have to keep in mind that the actual realization might not exclusively depend on monetary policy. Although the interbank rate is a fairly short-term interest rate, it may well be influenced also by other factors such as the overall prevailing business sentiment, the business cycle, and the degree of confidence among bankers. Accordingly, this might have implications for the forecast error that is at the center of interest in section 3. As interest rate projections of the CNB started at the time of the outbreak of the global financial crisis 2007/08

\footnotetext{
${ }^{1}$ Since October 2011, Norges Bank imposes quotas determining the size of deposits that commercial banks can place with the central bank. Deposits in excess of these quotas yield the sight deposit rate minus 100 basis points.
} 
and have spanned the entire post-crisis period, they cover a period of a more or less steadily declining interest rate trend.

\subsection{The USA}

The interest rate projections for the USA differ from the other four countries in that no single point forecast is made, but rather every Monetary Policy Report (published biannually), since 2012 contains a dot plot representing the results of a survey among all members of the FOMC. Members of the FOMC are asked about their individual assessments of the appropriate target federal funds rate by the end of the current year, as well as the end of the subsequent and following year, in two years, and in the longer run. The analysis in Sect. 4 makes use of all projections except for those for "the longer run," because it is difficult to clearly associate a realized interest rate to this forecast horizon in order to compute the forecast error. Since no FOMC member is obliged to submit an assessment about the appropriate target federal funds rate, the number of submitted forecasts in the data set varies and ranges from 16 to 19 for a single forecast period, resulting in a total of 208 forecasts across 12 Monetary Policy Reports since 2012. Due to the different data structure of the interest rate projections of the Federal Reserve, several analyses presented in Sects. 5 and 6 cannot be conducted in the same way for the USA as for the other countries.

\section{Interest rate projections and forecast rationality}

This section studies some general characteristics of the interest rate forecast errors. To this end, Fig. 1 plots the interest rate path (solid line) and the interest rate projections (dotted line) for each central bank. The figure suggests that there are periods, during which interest rate projections were consistently above or below the actual interest rate path. The Czech Republic (upper left panel) shows a somewhat ambiguous picture, as the forecast errors tend to be mostly positive between 2009 and 2012 and turn out flat after 2012, possibly suggesting a particularly strong case of forward guidance in the low interest rate period. In the case of New Zealand, findings are more distinctive and it is obvious that the forecast errors are negative for the period from roughly the beginning of the 2000s until the global financial crisis in 2008. The forecast errors become mostly positive as of 2009 , broadly reflecting the business cycle and the associated high- and low-interest rate environments. Detmers and Nautz (2012) already pointed out that most projection paths seem to show a "mean-reverting" behavior and suggest that the RBNZ published long-term interest rate projections in order to stabilize expectations whenever actual interest rates were seen as extraordinarily high or low. Norway and Sweden (lower panels) offer similar findings, albeit the pre-crisis tendency of underpredicting is not as distinctively visible compared to New Zealand due to the shorter time horizon. However, for the period since the global financial crisis in 2008, there is again a clear pattern of overpredicting the repo rate. In the case of Sweden, being a member of the European Union and given the proximity to the euro area, an indirect impact of the economic conditions and the monetary policy 

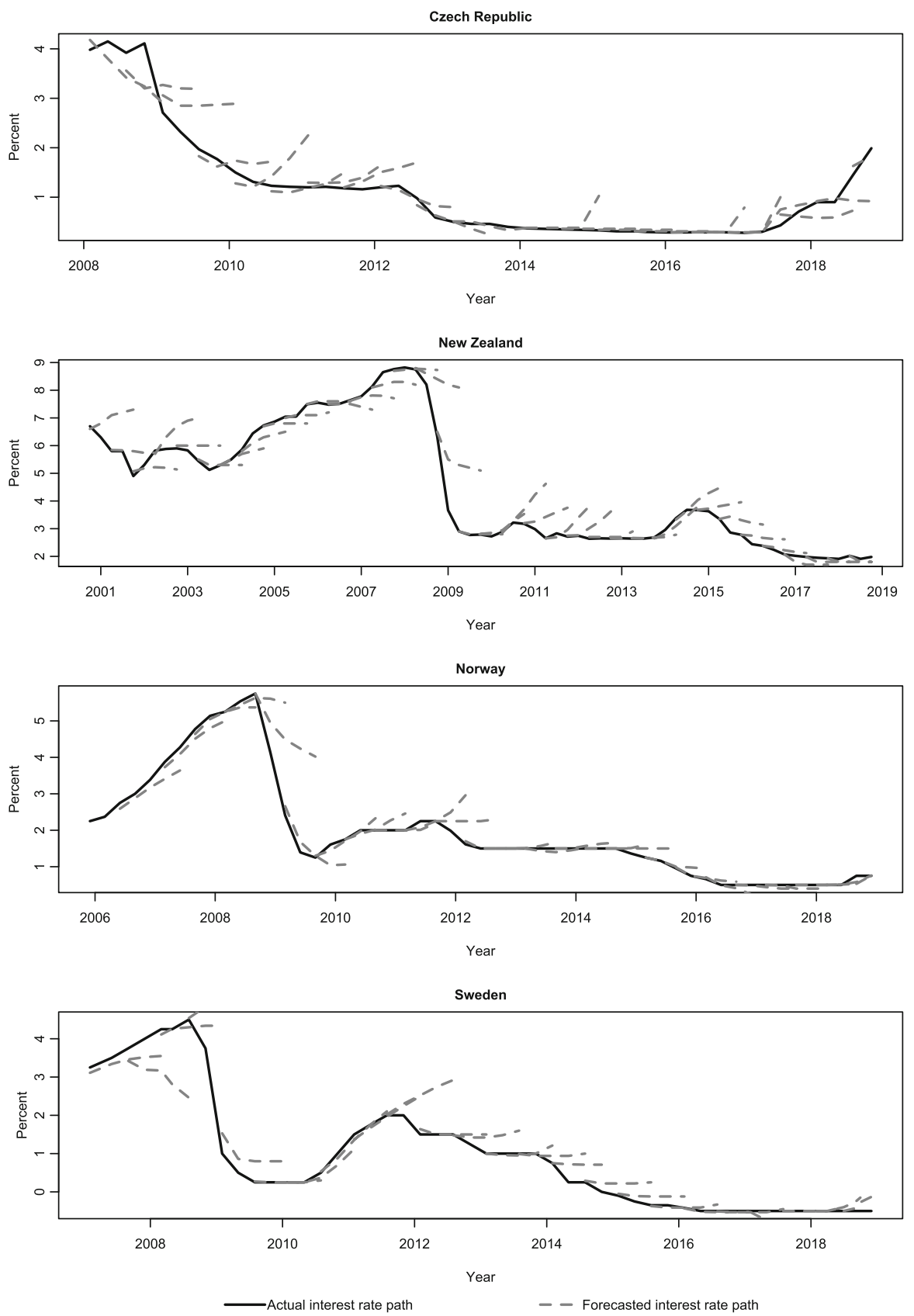

Fig. 1 Actual and projected interest rate paths. Note: figure 1 plots the actual interest rate paths (solid lines) against projected interest rate paths (dotted lines), beginning with the first published data of the respective central bank. Data are taken from the websites of the Česká Národní Banka, the Reserve Bank of New Zealand, the Norges Bank, and Sweden's Riksbank. Graphical representation of data from the US Federal Reserve was not possible due to the specifics of their data structure, as discussed in Sect. 2.5 
conducted by the European Central Bank cannot entirely be ruled out. The Swedish Krona, however, is officially a free-floating currency, and Sweden has no plans to join the euro area in the near future as reflected by its renunciation to join the European Exchange Rate Mechanism II, which is a precondition for joining the euro area later.

To empirically investigate the bias in the interest rate projections of central banks, Tables 2 and 3 report the results of a regression of the forecast error on a constant for different forecast horizons. The forecast error is defined as the difference between the realized interest rate at time $t+1$, which we denote as $r_{t+1}$, and the projected interest rate which was published at time $t$ for time $t+1$, denoted as $f_{t+1}$. For the Czech Republic, a statistically significant positive bias for the end-of-the month and 3-month horizons reflects that the CNB seems to have underpredicted interest rates. However, beyond the 9-month interest rate horizon, the CNB has systematically overpredicted the interest rate. For New Zealand, we find that with an increasing forecast horizon, a significant nonzero bias emerges in the forecast errors. More specifically, a negative bias in the forecast errors becomes visible and statistically significant starting at a 6-month forecast horizon. This result becomes even stronger with an increasing forecast horizon. In other words, the Reserve Bank of New Zealand shows a tendency to over-predict interest rates, which is also applicable to the forecast error bias regression results for Norway, albeit somewhat weaker in both effect and statistical significance especially for the shorter forecast horizons. Table 2 reveals that a negative bias in Norges Bank's interest rate forecasts manifests itself at a statistically significant level for all forecast horizons beyond 9 months. The case of Sweden shows the same phenomenon as already reported for New Zealand and Norway. As for New Zealand, a negative bias in forecast errors becomes statistically significant for forecast horizons beyond 6 months. Again, with increasing horizons, the bias becomes stronger in both size and statistical significance. Similarly, Table 3 reports an increasing negative bias in the forecast errors with increasing forecast horizons for the USA.

To further test the unbiasedness of interest rate projections, we follow Holden and Peel (1990), Chortareas et al (2012) and Cohen et al (2015) in their notion that the joint hypothesis based on a bivariate regression is a sufficient but not necessary condition, which in turn over-rejects the null hypothesis of unbiasedness. Hence, we follow Holden and Peel (1990) and Cohen et al (2015) by using a univariate test of biasedness, since it tests for both necessary and sufficient conditions. The results in Table 4 for the 3-month forecast horizon using two auxiliary variables, inflation and economic growth, appear mixed. The column "efficiency" reports the $p$-values of the estimated coefficients, which vary across instruments and central banks. In most cases, the estimated coefficient is not statistically significant, indicating that the unbiasedness condition is fulfilled.

In addition, we apply a martingale test of the forecasts and a convergence test of the forecast errors. The martingale test investigates whether forecast revisions are uncorrelated to the information set available to the forecaster. To be consistent in our analysis, we again use inflation measured by the change in the consumer price index (CPI) and the real GDP growth rate as available information sets for each and every interest rate forecast revision. Following Batchelor and Dua (1991), we estimate:

$$
f_{i, t-h, t}-f_{i, t-h-1, t}=\alpha+\beta_{i} x_{i, t-h-1}+\epsilon
$$




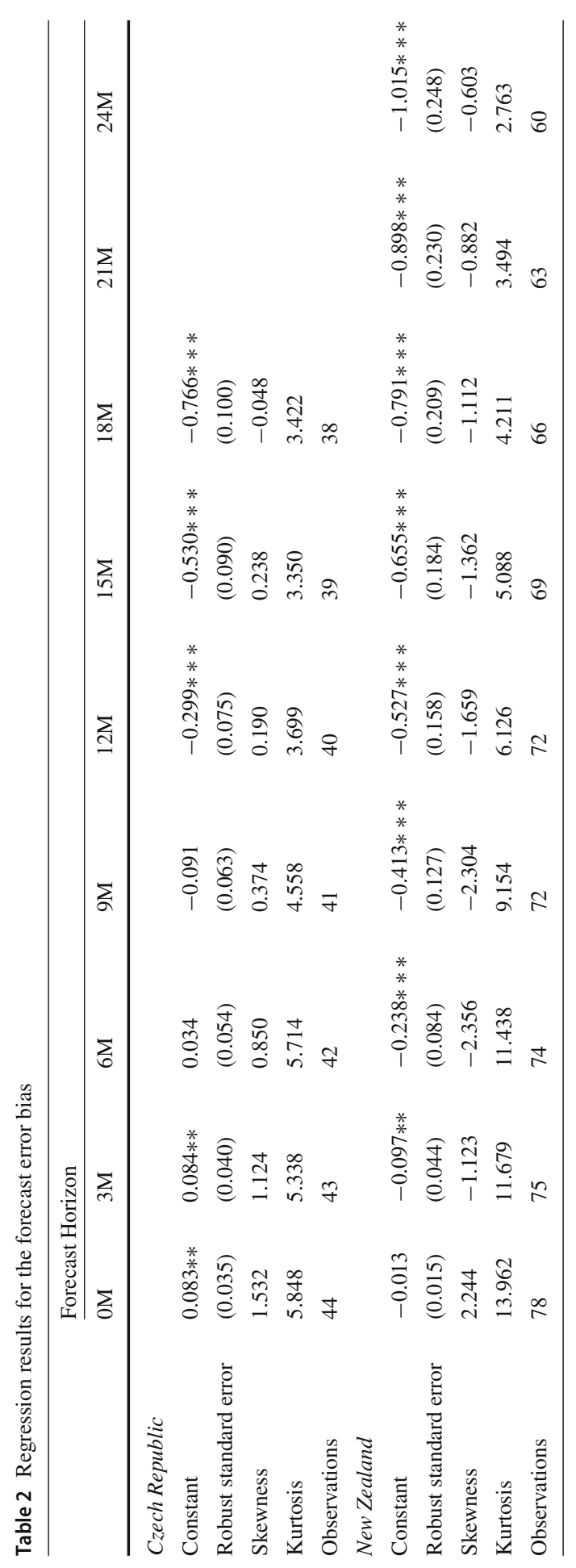




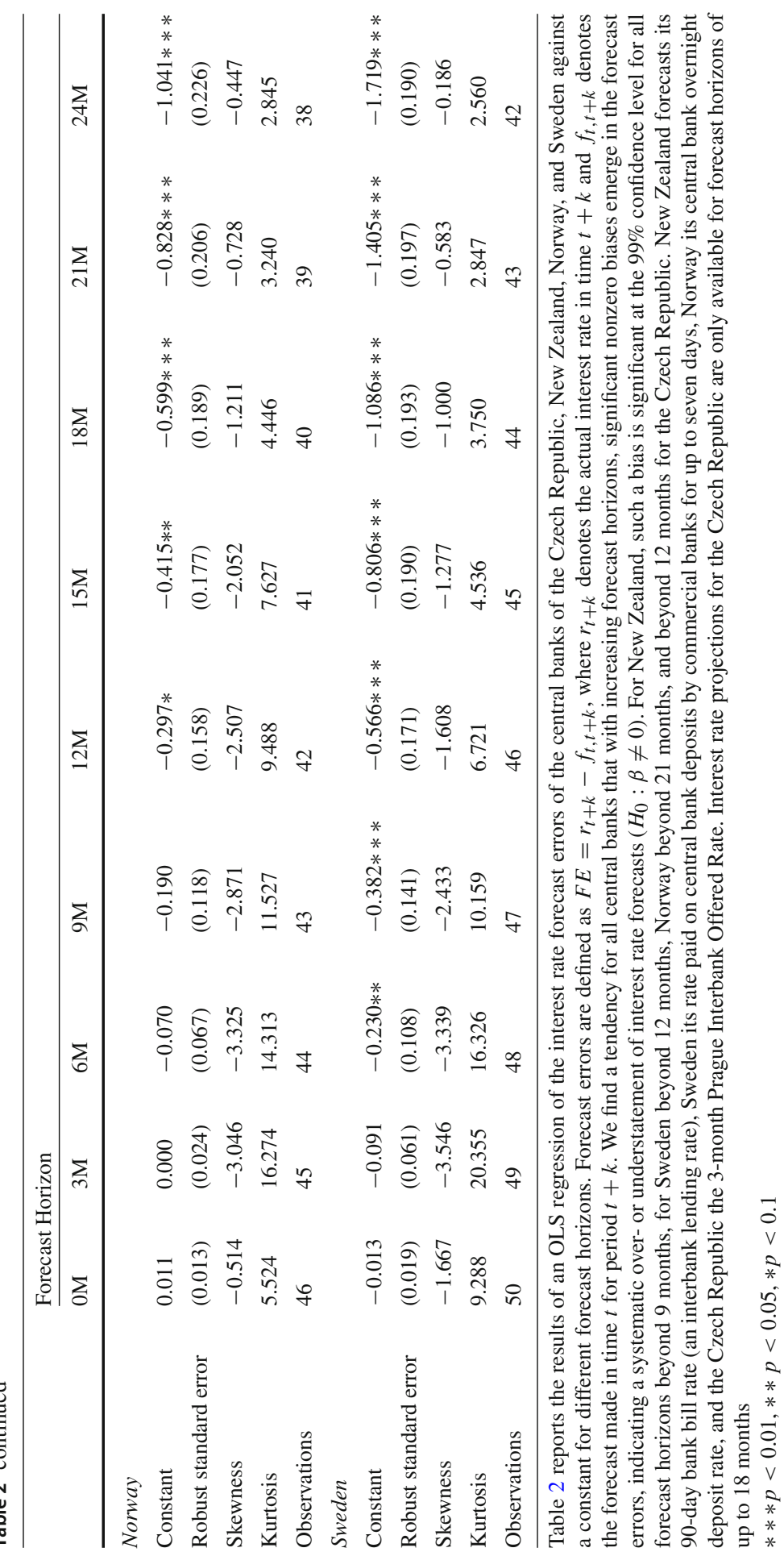


Table 3 Regression results for the forecast error bias of the Federal Reserve

\begin{tabular}{llll}
\hline & \multicolumn{2}{l}{ Forecast horizon } & \\
\cline { 2 - 4 } & End of current year & End of next year & End of two years \\
\hline Constant & $-0.188 * * *$ & $-0.582 * * *$ & $-1.094 * * *$ \\
Robust standard error & $(0.029)$ & $(0.055)$ & $(0.075)$ \\
Skewness & -0.2667 & -1.171 & -0.428 \\
Kurtosis & 5.678 & 4.454 & 2.318 \\
Observations & 239 & 208 & 175 \\
\hline
\end{tabular}

Table 3 reports the results of a simple OLS regression of the interest rate forecast errors of the Federal Reserve on a constant for different forecast horizons. We find significantly negative biases in the forecast errors, indicating a systematic overstatement of interest rate forecasts $\left(H_{0}: \beta \neq 0\right)$

$* * * p<0.01, * * p<0.05, * p<0.1$

where $f_{i, t-h, t}-f_{i, t-h-1, t}$ denotes the forecast revision of forecaster $i$ at time $t$ for forecast horizon $h$ and $x_{i, t-h-1}$ the available information set at the time the forecast was made. The martingale condition can then be tested by testing the restriction $\beta_{i}=0$.

The convergence test analyses whether the error variance is non-increasing as the forecast horizon shortens. This test is applied by Batchelor and Dua (1991), Muth (1961), Patton and Timmermann (2012) and requires the forecast error variance not to increase as the forecast horizon shortens.

Our results indicate that the martingale condition is not consistently met by the interest rate projections of the central banks of the Czech Republic, New Zealand, Norway, and Sweden. Table 5 reports the estimated results of the regression as specified in equation (1) and shows that none of the four countries consistently meet the martingale condition as indicated by statistically significant regression coefficients. For the Czech Republic, the estimated coefficients are statistically significant in 7 out of 18 cases across forecast horizons and information sets and therefore fail to meet the martingale condition. For New Zealand, the coefficient estimates are statistically significant in 8 out of 27 cases, for Norway in 9 out of 27 cases, and for Sweden in 18 out of 27 . Whereas for the Czech Republic it is difficult to point out a variable that seems somewhat consistently correlated with its forecast revisions, the inflation rate is statistically significantly correlated with the interest rate forecast revisions of New Zealand for 5 out of 9 forecast horizons and for 8 out of 9 forecast horizons in Sweden. Economic growth produces statistically significant regression coefficients for 6 out of 9 forecast horizons in Sweden, and unemployment appears to be correlated with Norway's forecast revisions for 7 out of 9 forecast horizons. Overall, the martingale condition is best satisfied by the forecast revisions in New Zealand as indicated by the lowest number of statistically significant correlations between revisions and information sets across all forecast horizons. Norway closely follows with only one more instance, and the Czech Republic comes in third. Sweden's forecast revisions seem to be most strongly and consistently correlated with the contemplated information sets of all four central banks.

Regarding the convergence criterion, Fig. 2 depicts the forecast error variance for all four central banks for decreasing forecast horizons. In the case of the Czech Republic, 


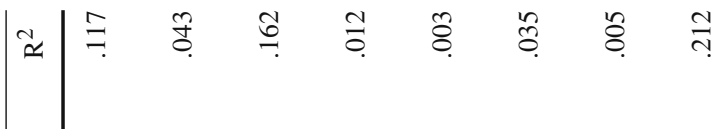

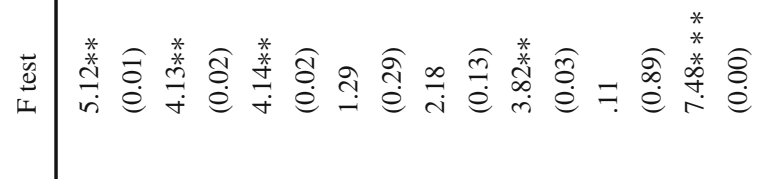

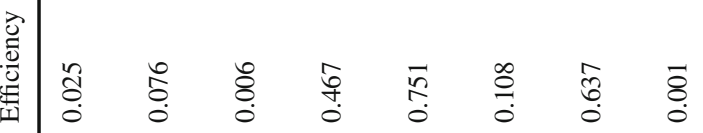

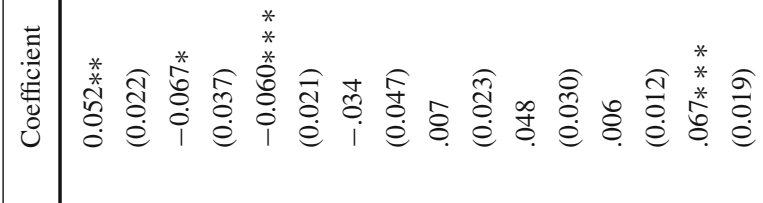

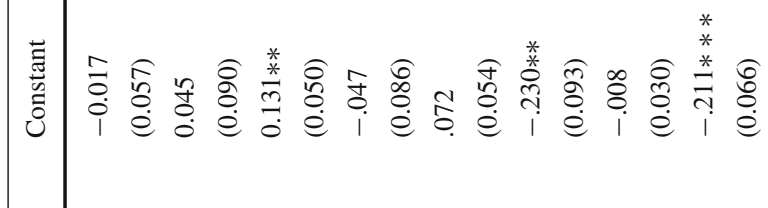

$$
\begin{aligned}
& \text { 竞 } \\
& \text { 荧 }
\end{aligned}
$$

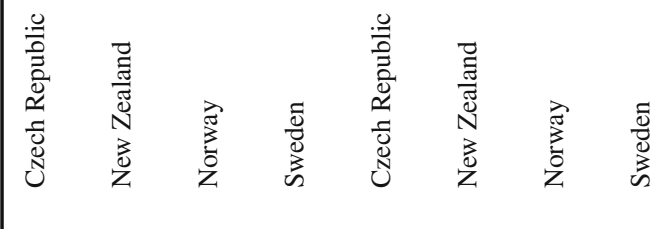$$
\text { 总 }
$$ 


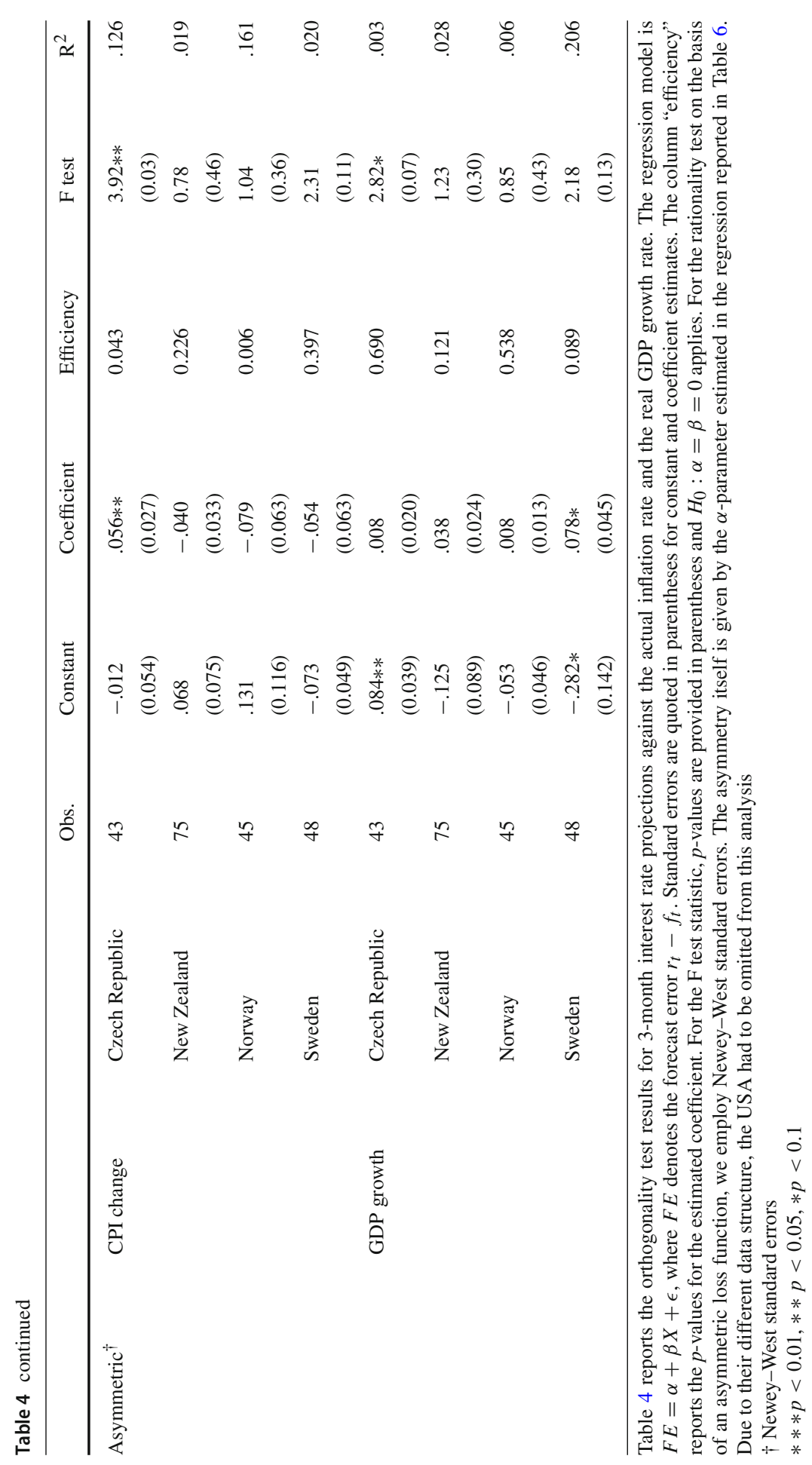




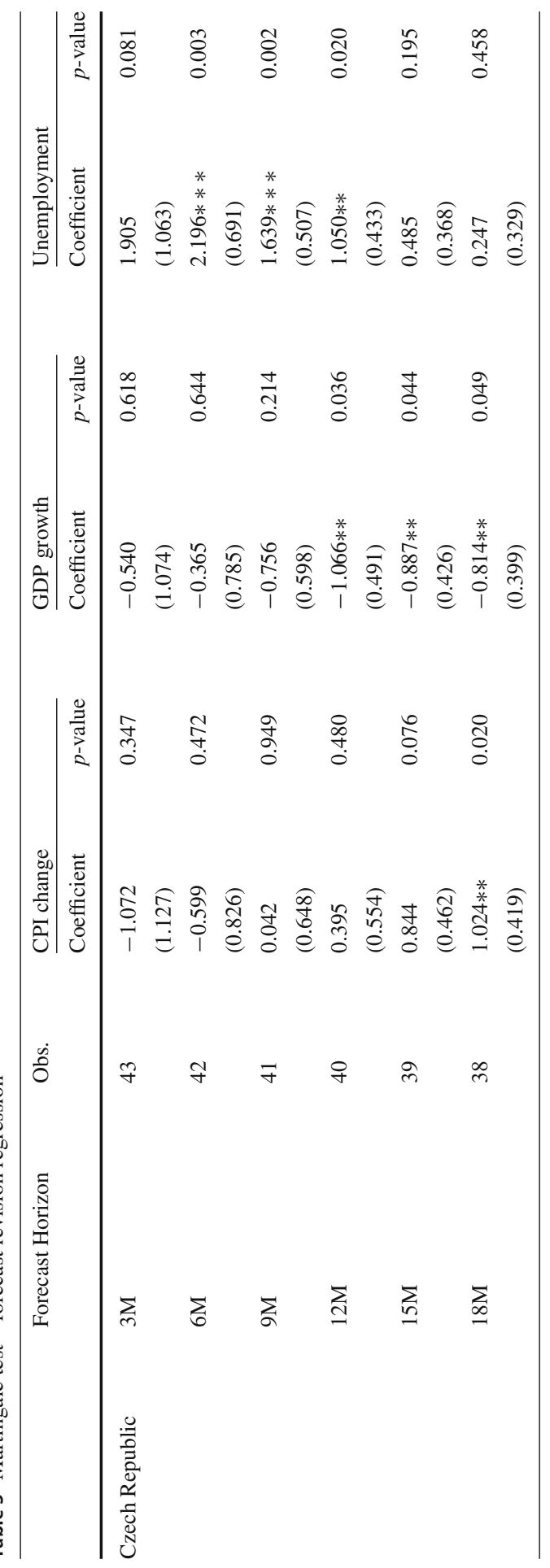




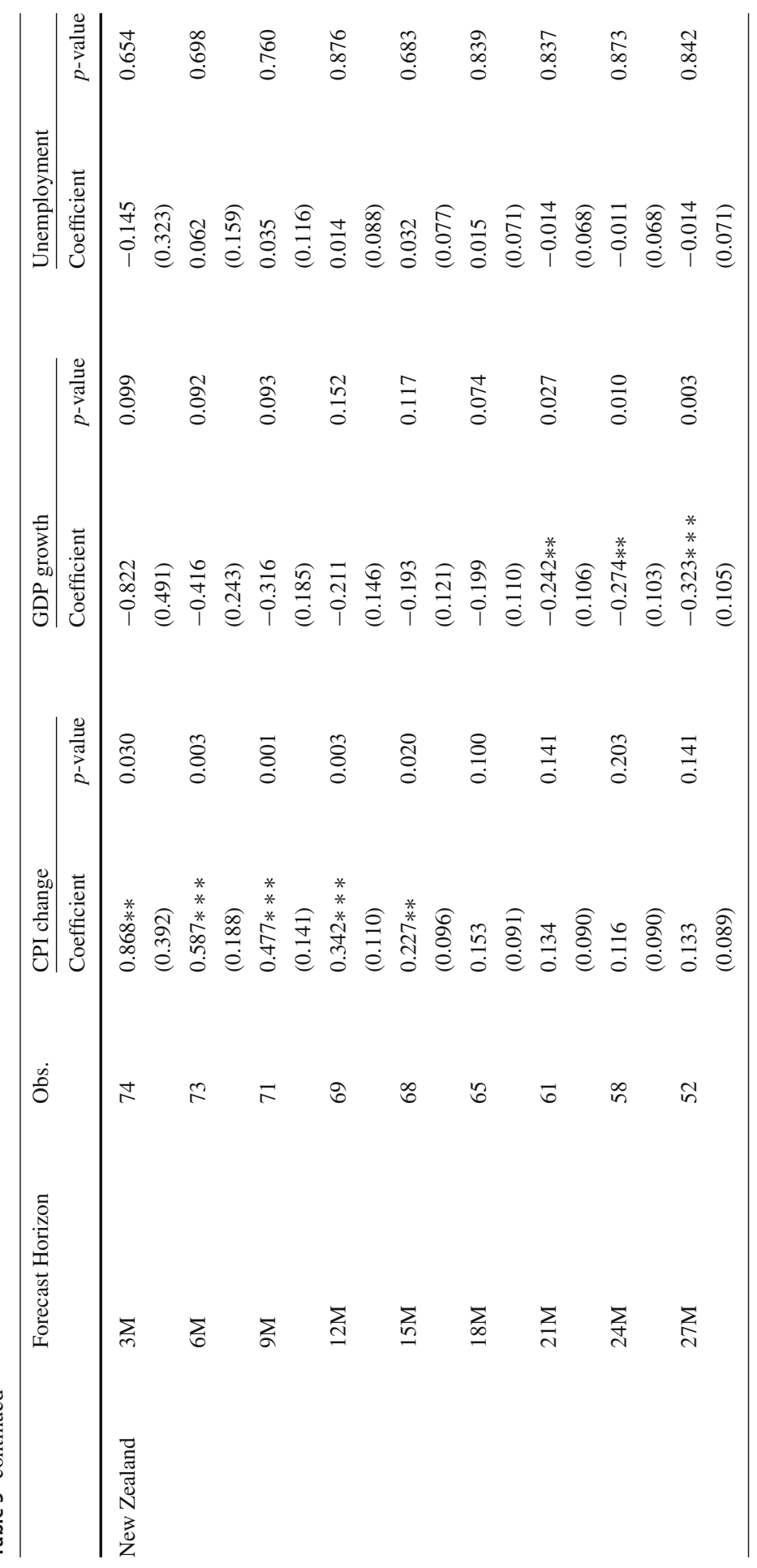




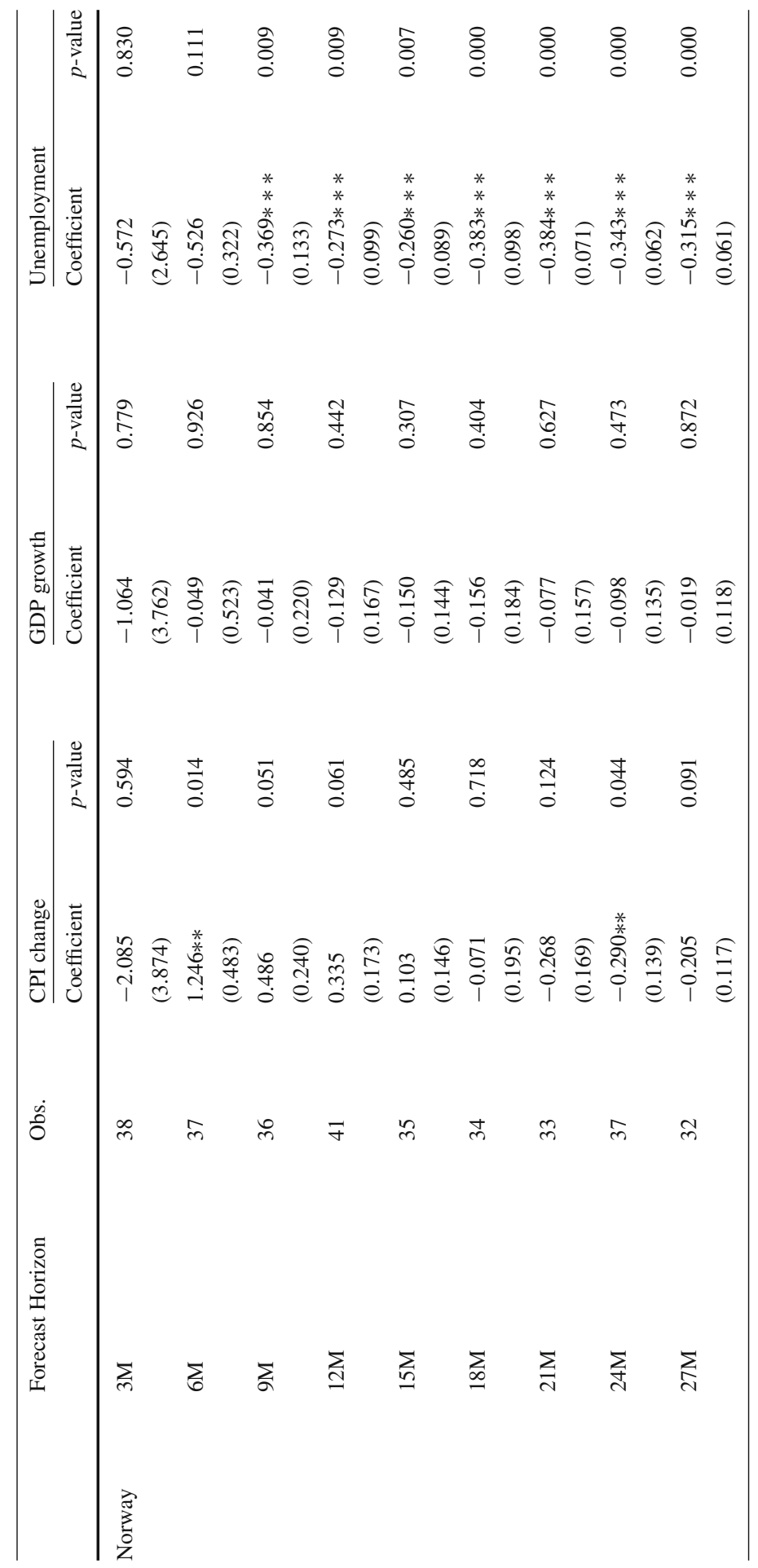




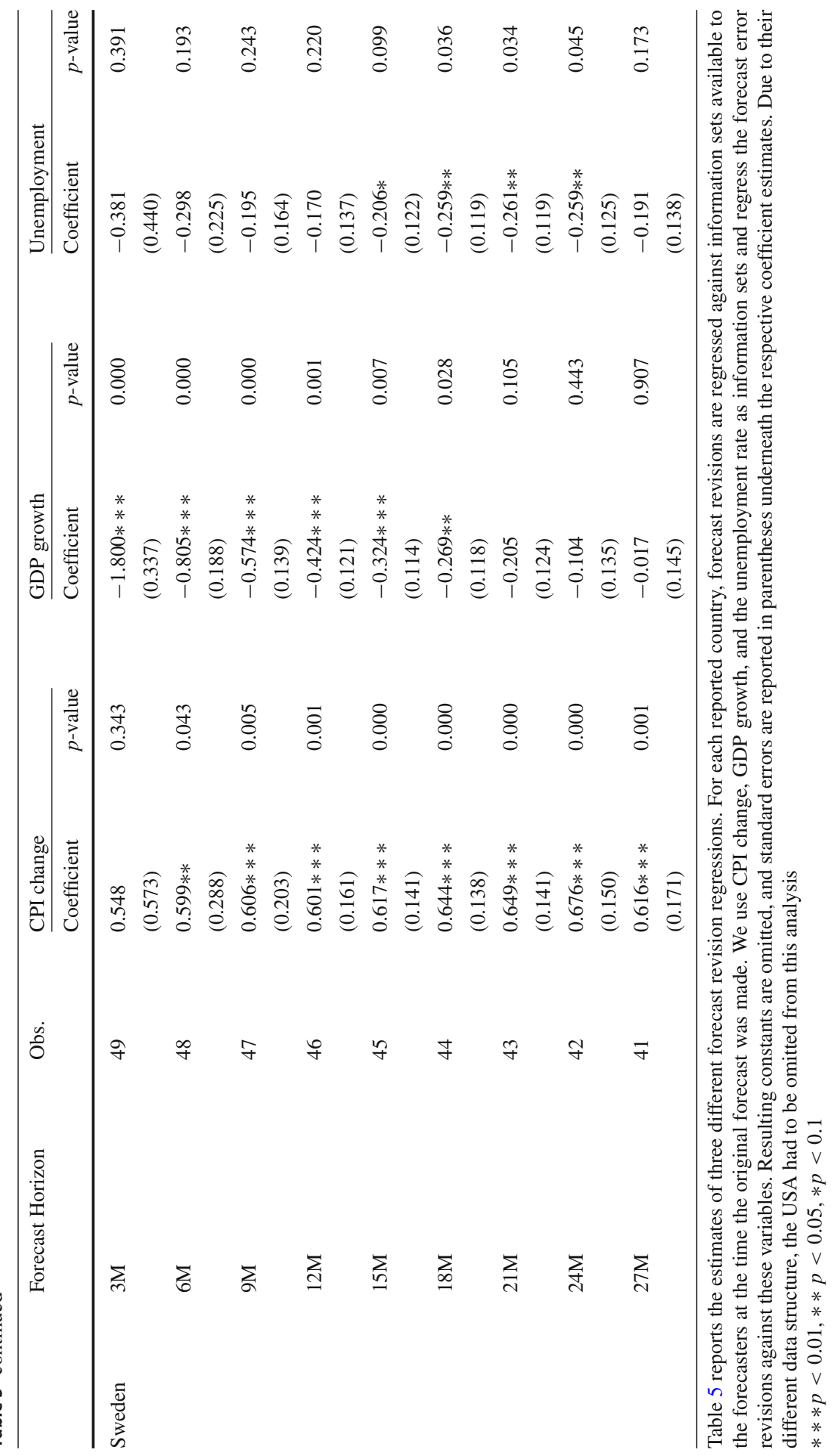



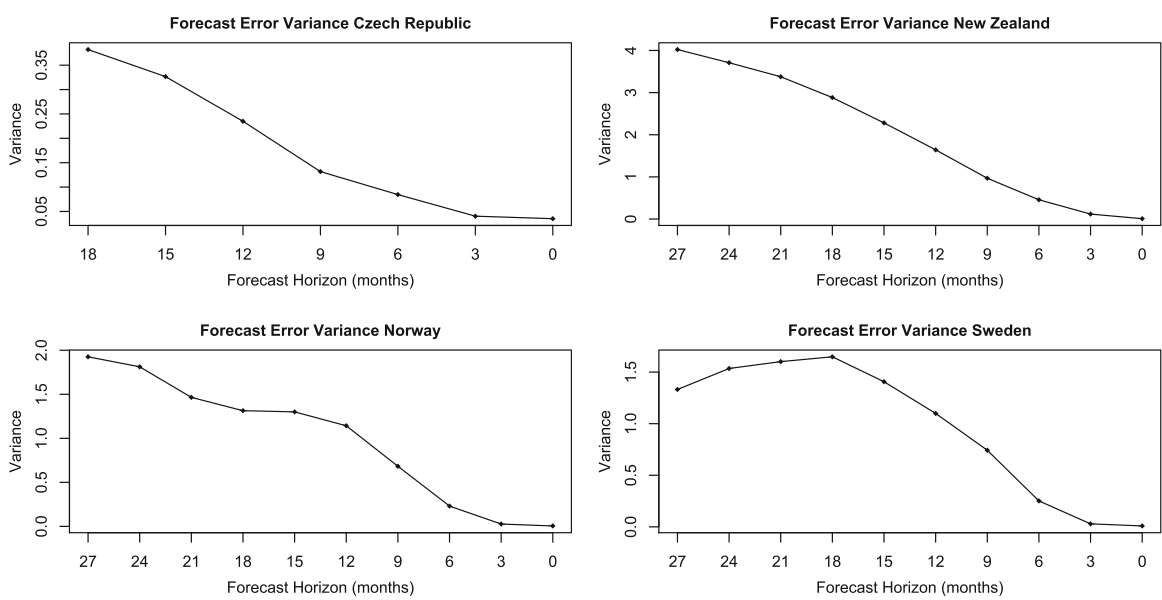

Fig. 2 Convergence test-forecast error variances. Note: figure 2 plots the forecast error variance across forecast horizons for the central banks of the Czech Republic, New Zealand, Norway, and Sweden. All four central banks show a tendency of decreasing forecast error variance with decreasing forecast horizons. This is consistent with the convergence criterion of rational forecasts. Due to their different data structure, the USA had to be omitted from this representation

New Zealand, and Norway, forecast error variance clearly decreases with decreasing forecast horizons, albeit the amount by which forecast error variance is decreasing varies considerably. In the case of Sweden, the convergence condition requiring forecast error variance to be non-increasing with shortening forecast horizons is not met. Between forecast horizons of 18 and 27 months, the forecast error variance is clearly increasing as shown in Fig. 2.

Overall, forecast rationality as defined by the unbiasedness, orthogonality, convergence, and martingale conditions cannot be empirically supported for the interest rate forecasts of the Czech Republic's, New Zealand's, Norway's, and Sweden's central banks.

\section{The econometric model}

In this section, we examine the bias in forecast errors in more detail by assuming that central banks are based on an asymmetric loss function. Unlike traditional tests of forecast rationality, which regress the forecast error on a set of variables, the asymmetric loss function renders it possible to weight overprojections and underprojections differently. More formally, we apply the approach developed by Elliott et al (2005) which indicates that a central bank minimizes the observed forecast errors by assuming the following general central bank's loss function, $\mathcal{L}$ :

$$
\mathcal{L}=\left[\alpha+(1-2 \alpha) I\left(r_{t+k}-f_{t, t+k}<0\right)\right]\left|r_{t+k}-f_{t, t+k}\right|^{p},
$$

where $I$ refers to an indicator function which accounts for the asymmetric forecast error, $p$ reflects the functional form with $p=1(=2)$ representing a linear (quadratic) 
loss function, and $k$ denotes the forecast horizon. In case of $\alpha=0.5$ and $p=1$, the loss function is symmetric and reduced to $\mathcal{L}=0.5\left|r_{t+k}-f_{t, t+k}\right|$ which is consistent with the traditional tests for rationality. In this case, forecasts that turn out to be higher than the observed value later (i.e., overpredictions) lead to the same loss as equivalent forecasts that turn out as too low (i.e., underpredictions). In both cases, the loss is linear in the forecast error and its graph is V-shaped. If, however, $p=2$, then the quadratic symmetric loss function underlies a traditional Mincer-Zarnowitz regression of forecast unbiasedness and the loss increases over-proportionately with the size of the overpredictions and underpredictions. In this case, the loss function takes on the shape of a parabola. However, as long as $\alpha=0.5$, it is symmetric around the zero forecast error. For values of $\alpha$ smaller or greater than 0.5 , the loss function becomes asymmetric. If, for example, $\alpha=0.4$, the loss function (for $p=1$ ) becomes $\mathcal{L}=\left[0.4+0.2 \cdot I\left(r_{t+k}-f_{t, t+k}<0\right)\right]\left|r_{t+k}-f_{t, t+k}\right|$. In this case, if $r_{t+k}-f_{t, t+k}>0$ (underprediction), the expression in brackets is 0.4 . However, if $r_{t+k}-f_{t, t+k}<0$ (overprediction), the expression in brackets is 0.6. Hence, an overprediction is more harmful than an underprediction. The asymmetry is in the opposite direction if $\alpha>0.5$. In our empirical analysis, we follow the notion to look for the shape of the loss function that is most consistent with the observed forecast errors of a central bank. If we find that $\alpha$ is not significantly different from 0.5 , we conclude that central banks indeed have a symmetric loss function. Any value for $\alpha$ significantly different from 0.5 in reverse indicates the existence of an asymmetric loss function. We also assume that the loss from interest rate forecast errors can be modeled separately from the loss from, for example, inflation rate forecast errors.

Elliott et al (2005) report that given the functional form of the loss function $p$, the following general method of moments (GMM) estimator yields a consistent and unbiased estimate of the asymmetry parameter: $\hat{\alpha}$.

$$
\hat{\alpha}=\frac{\left[\frac{1}{T} \sum_{t=\tau}^{T+\tau-1} v_{t}|F E|^{p-1}\right]^{\prime} \hat{S}^{-1}\left[\frac{1}{T} \sum_{t=\tau}^{T+\tau-1} v_{t} I(F E<0)|F E|^{p-1}\right]}{\left[\frac{1}{T} \sum_{t=\tau}^{T+\tau-1} v_{t}|F E|^{p-1}\right]^{\prime} \hat{S}^{-1}\left[\frac{1}{T} \sum_{t=\tau}^{T+\tau+1} v_{t}|F E|^{p-1}\right]},
$$

where $F E$ is the forecast error and generally defined as

$$
F E=r_{t+k}-f_{t, t+k}
$$

and $\hat{S}=\frac{1}{T} \sum_{t=\tau}^{T+\tau-1} v_{t} v_{t}^{\prime}(I(F E<0)-\hat{\alpha})^{2}|F E|^{2 p-2}$ denotes a weighting matrix, $v_{t}$ $=$ vector of instruments, and $T=$ number of forecasts available (starting at $t=\tau+1$ ). We use as instruments a constant (Model 1), the lagged actual interest rate (Model 2), and the professional forecasts of Consensus Economics for interest rates in each country (Model 3). Additionally, we also test for rationality of forecasts by computing a J-test statistic as proposed by Elliott et al (2005). To produce a forecast error different from zero may seem irrational at first glance; however, the rationality hypothesis might change when considering an underlying, asymmetric loss function. More specifically, we perform a test for rationality by computing a J-test statistic using a $\chi^{2}$ distribution:

$$
J(\hat{\alpha})=\hat{E} \frac{1}{T}\left(x_{t}^{\prime} \hat{S}^{-1} x_{t}\right) \sim \chi_{d}^{2}
$$


where $x_{t}=\sum_{t=\tau}^{T+\tau-1} v_{t}\left[I\left(r_{t, t+k}-f_{t, t+k}<0\right)-\hat{\alpha}\right]\left|r_{t+k}-f_{t, t+k}\right|^{p-1}$ and $d$ is the number of instruments. To conduct the test under the assumption of symmetric loss, we set $\alpha=0.5$ and examine the J-test statistic, which is, in this case, distributed as $J(0.5) \sim \chi_{d}^{2}$. If forecast rationality is rejected, this may well be caused by the underlying symmetry assumption, which is why we compute another test statistic by allowing for asymmetric loss, i.e., $\alpha \neq 0.5$. By comparing $J(\hat{\alpha})$ with $J(0.5)$, we can assess whether using an estimated asymmetric loss function rather than an invoked symmetric loss function weakens evidence against forecast rationality.

\section{Estimation results}

Table 6 reports the estimation results of the asymmetry parameters $\hat{\alpha}$ and for forecast rationality under a symmetric $J_{2}(0.5)$ and asymmetric $J_{2}(\hat{\alpha})$ loss for all central banks considered. Estimates were performed for nine forecast horizons and for both a linear and quadratic loss function. Results reported here refer to the estimates of the asymmetry parameter $\hat{\alpha}_{1}$, in which a constant is used as an instrument. Additionally, two other instruments were used as well: $\hat{\alpha}_{2}$ denotes asymmetry parameters that were estimated using the lagged actual interest rate as an instrument. These yield qualitatively very similar results to the estimates using a constant. Forecast errors of the professional interest rate forecasts by Consensus Economics were also used as an instrument and are shown as $\hat{\alpha}_{3}$.

Four main findings can be highlighted. First, for the current-month ${ }^{2}$ forecasts, only the estimates for New Zealand suggest with statistical significance (independent of the linearity or nonlinearity of the assumed loss function) that the parameter $\alpha$ is 0.5 and, thus, the central bank of New Zealand values overpredictions and underpredictions equally. The USA exhibits an asymmetric loss function for the end-of-year forecasts by consistently producing an asymmetry parameter greater than 0.5 across linear and quadratic loss function specifications. For the other central banks, the picture is more mixed and does not rule out an asymmetric loss function. This finding is valid for threemonth forecasts as well. The central bank of Norway more or less consistently exhibits an asymmetry coefficient of lower than 0.5 in the linear as well as in the quadratic specification, while for the Czech Republic and Sweden, the asymmetry parameter estimates vary greatly when moving from a linear to quadratic loss function.

Second, comparing the different $\hat{\alpha}$ estimates across all forecast horizons as illustrated in Fig. 3 suggests that for the 6-month forecast horizon the $\hat{\alpha}$ estimates are consistently closer to 0.5 than for other forecast horizons. This suggests that this is the time frame for which central banks aim at making as accurate forecasts as possible. A possible explanation for this could be that central banks consider the 6-month forecast horizon to be a "sweet spot" for forward guidance, possibly based on their experience that this forecast horizon is most effective in steering expectations.

Third, for forecast horizons of more than 6 months, central banks examined here show asymmetry parameters that are greater than 0.5 in the majority of the cases.

\footnotetext{
2 Interest rate projections with a one-month forecast horizon, i.e., predicting the interest rate for the end of the month.
} 


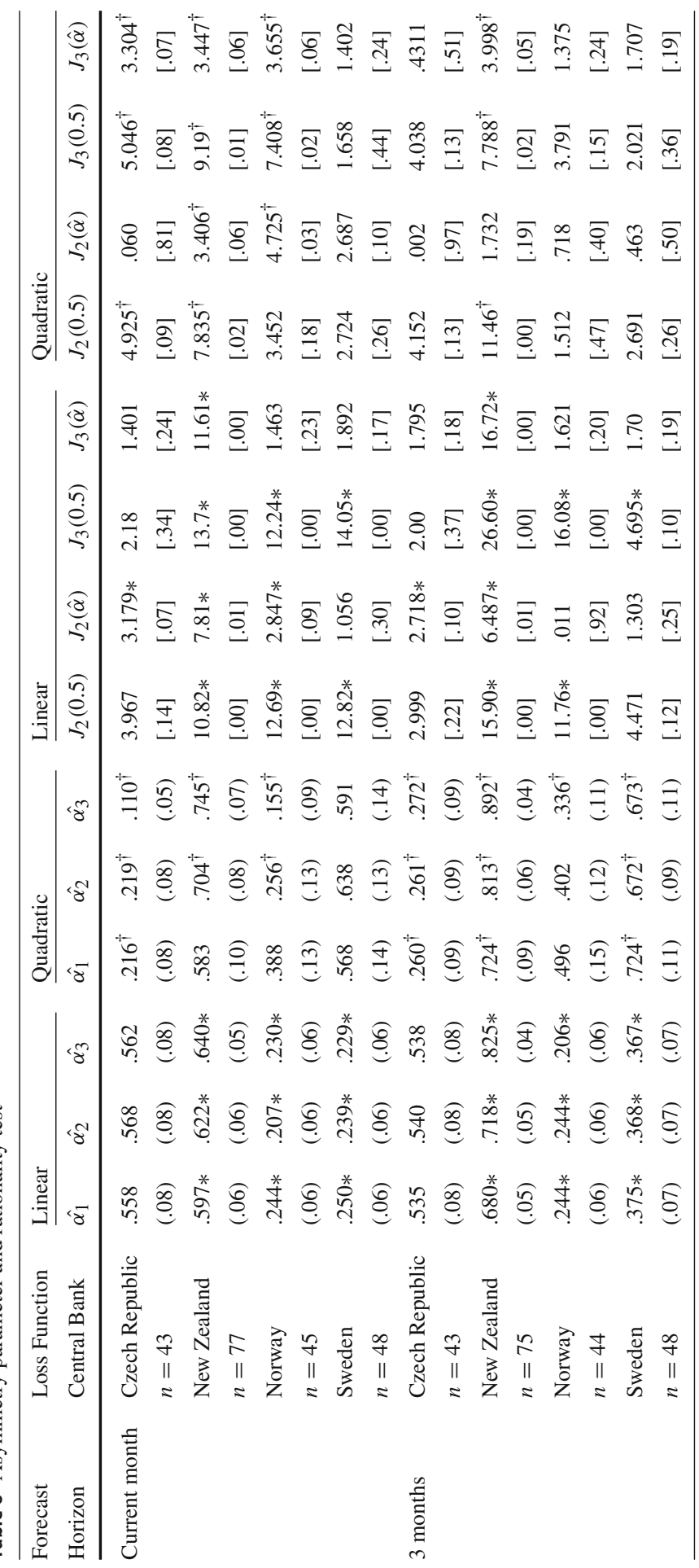




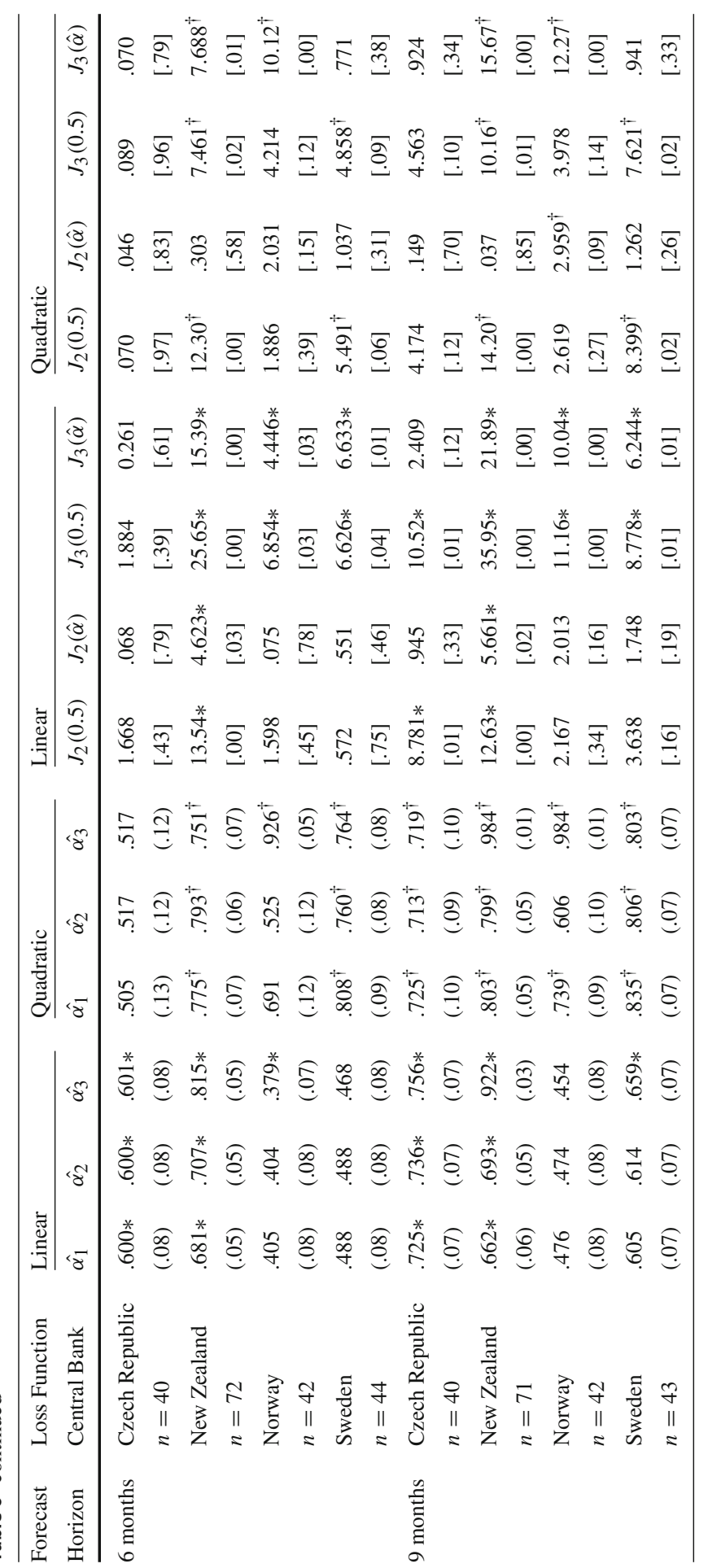




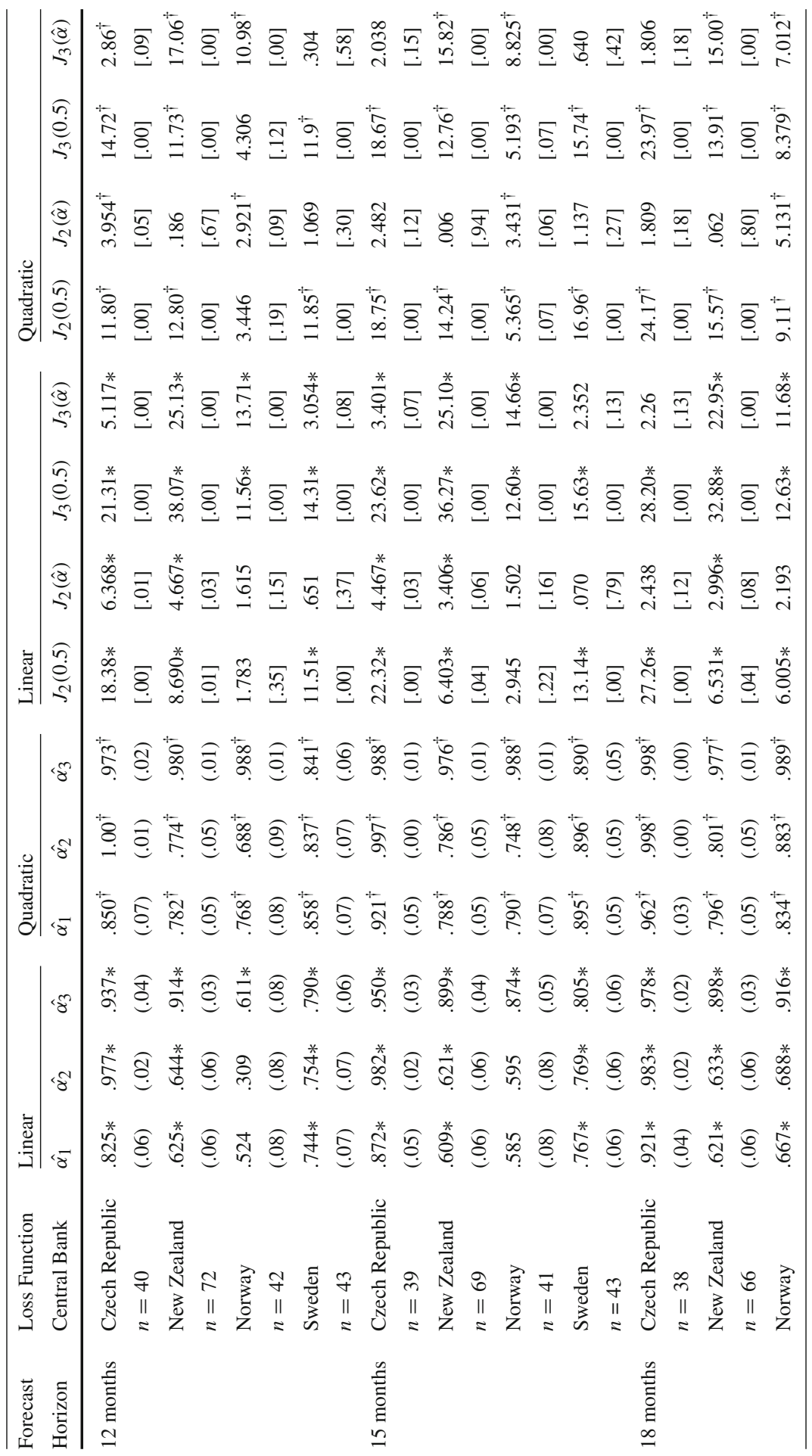




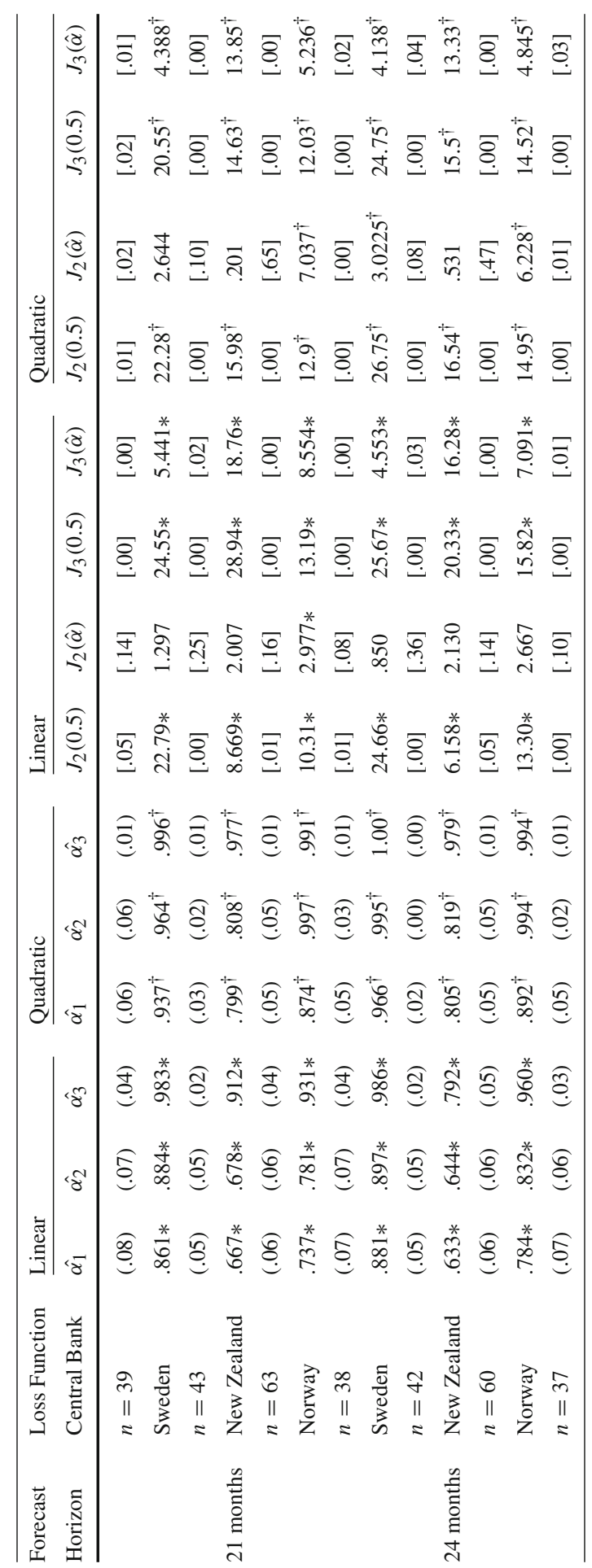




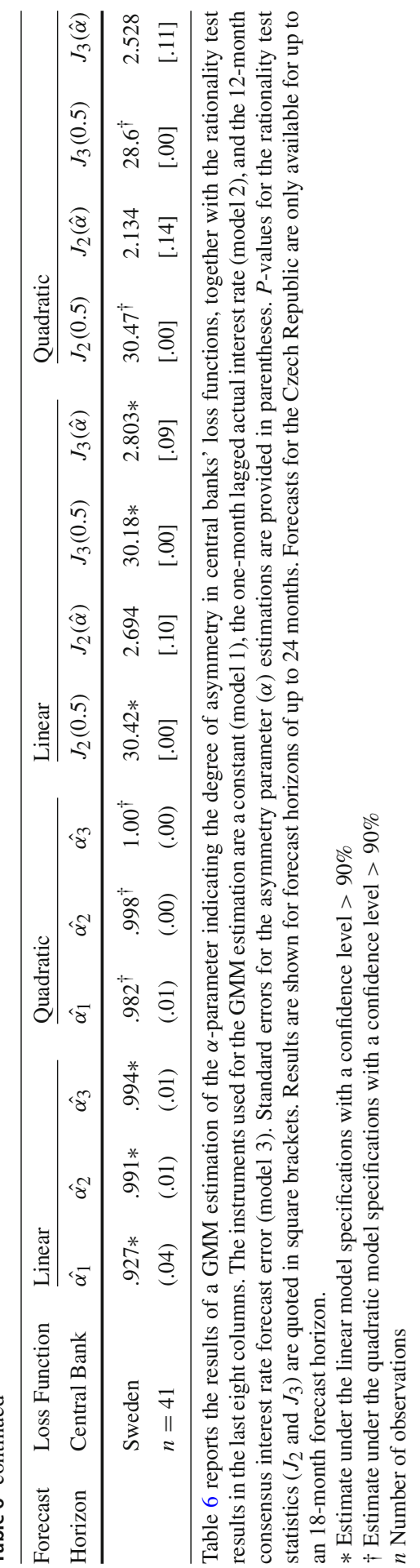



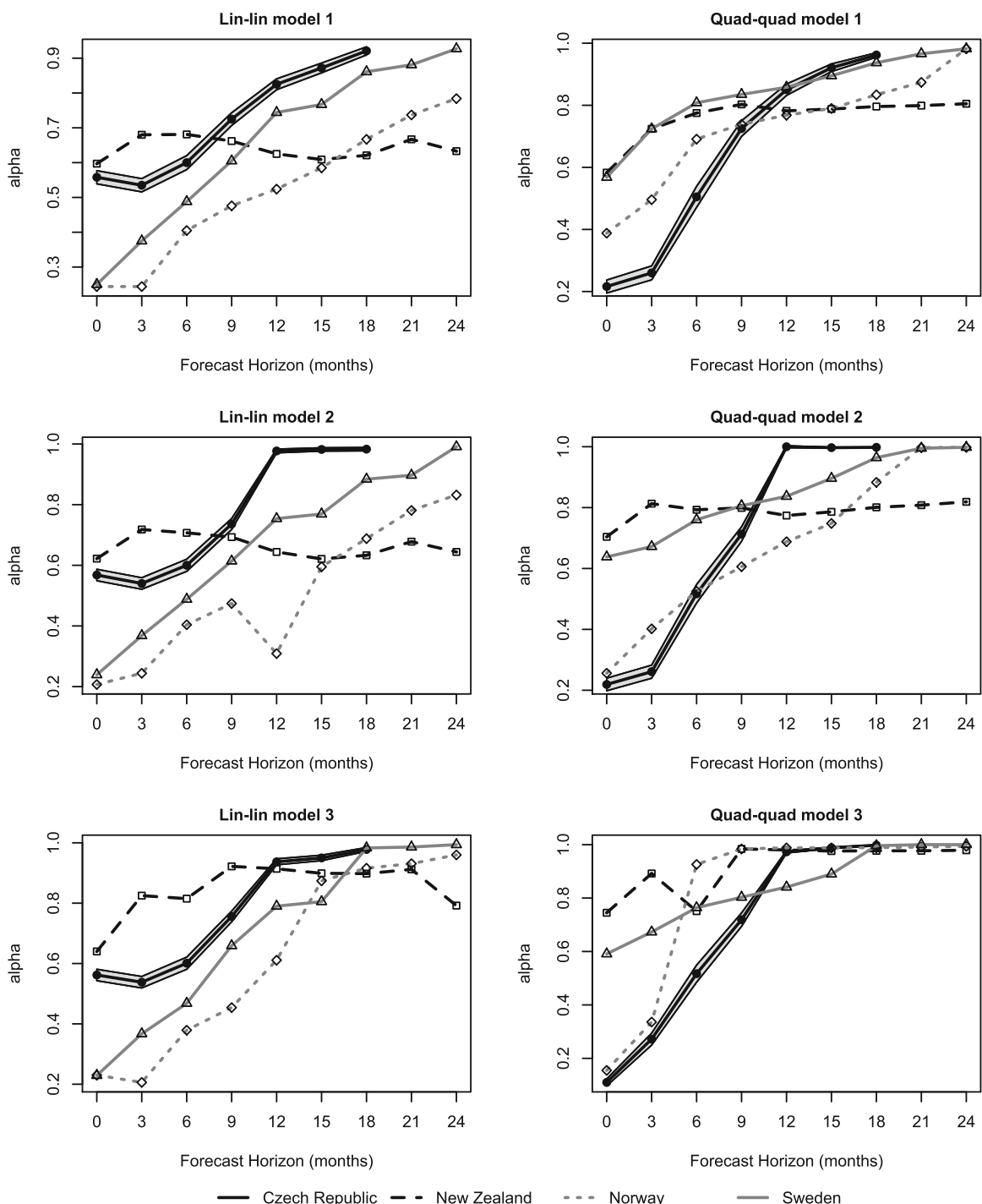

Fig. 3 Asymmetry parameter estimates across forecast horizons. Note: figure 3 plots the $\alpha$ estimates along forecast horizons for the four different model specifications. By visual appraisal, 6 months seem to be most consistently the forecast horizon where the $\alpha$ estimates are closest to 0.5 across central banks and models. Gray-shaded area indicates $90 \%$-confidence band of estimates for the Czech Republic. For lucidity purposes, the other confidence bands are omitted from this figure but available upon request. Due to their different data structure, the USA had to be omitted from this representation 
This indicates that the central banks associate underprojections of their interest rate forecast with higher costs. Apparently, they prefer to overpredict the future interest rate path. One possibility is that they use their interest rate forecasts to leave room for unannounced interest rate cuts at the expense of a lower forecast accuracy. This would be in line with our initial considerations, according to which there may be a trade-off between providing accurate forecasts and pursuing macroeconomic stability. Such considerations may play a more important role only for longer forecast horizons. Further testing for rationality confirms for most cases that rationality of central banks' forecasts cannot be rejected at a statistically significant level when assuming an asymmetric loss function. More specifically, the Hansen J-tests for overidentification performed for all $\hat{\alpha}$ estimations shown in Tables 6 and 7 indicate that for 83 out of 136 cases, the significance level of the $J_{2}$ test statistic decreases and the rationality hypothesis therefore becomes harder to reject.

Fourth, the results do not indicate that the loss function is generally linear or quadratic. In about $60 \%$ of the cases, the estimates of the loss function for a given central bank and forecast horizon are relatively similar for the two specifications. For the rest of the cases, there is no clear sign which specification dominates. The similarity of the estimates for the linear and the quadratic specification may be a result of the generally small magnitude of the forecast errors. In this case, large errors, which would weigh heavily in a quadratic specification, are very much the exception.

Figure 4 visualizes the estimated linear loss functions for all central banks. When $\alpha$ is estimated to be smaller than 0.5 , the graph of the loss function is steeper for negative values of the forecast error $r_{t+k}-f_{t, t+k}<0$ (overprediction) than for positive values of the forecast error (underprediction). This can be found more often for shorter than for longer forecast horizons. As in the example of New Zealand, the panel "current month" indicates that an $8 \%$ underprojection of the interest rate (point A) yields the same loss as a $5.4 \%$ overprojection (point B). With increasing forecast horizons, the graphs of most loss functions clearly turn counterclockwise. For quadratic loss functions (shown in Fig. 5), the convergence effect is even more pronounced. As a consequence, in the case of New Zealand, the central bank has the highest preference of overprojection for the 21-month forecast horizon. Here, point $\mathrm{C}$ indicates that an 8 $\%$ overprojection (negative forecast error) yields the same loss for the Bank of Norway as a $4.0 \%$ underprojection (point D).

Tables 4 and 8 report the results of orthogonality tests conducted on a variety of economic variables in order to identify possible systematic relationships between central bank forecast errors and some economic measure of interest. More specifically, we test for orthogonality of interest rate forecast errors and the lagged actual interest rate, the actual inflation rate, the real GDP growth rate, and the actual unemployment rate. To conduct this test, we estimate the following regression model:

$$
r_{t}-f_{t}=\alpha+\beta X_{t}+\epsilon
$$

where $r_{t}-f_{t}$ denotes the forecast error and $X_{t}$ a vector of economic variables. Orthogonality between forecast errors and the economic variable in question is tested for by computing an $\mathrm{F}$ test statistic hypothesizing $\alpha=\beta=0$. This null hypothesis implies rationality since an $\alpha$ coefficient and $\beta$ coefficient of zero indicate no influence of 


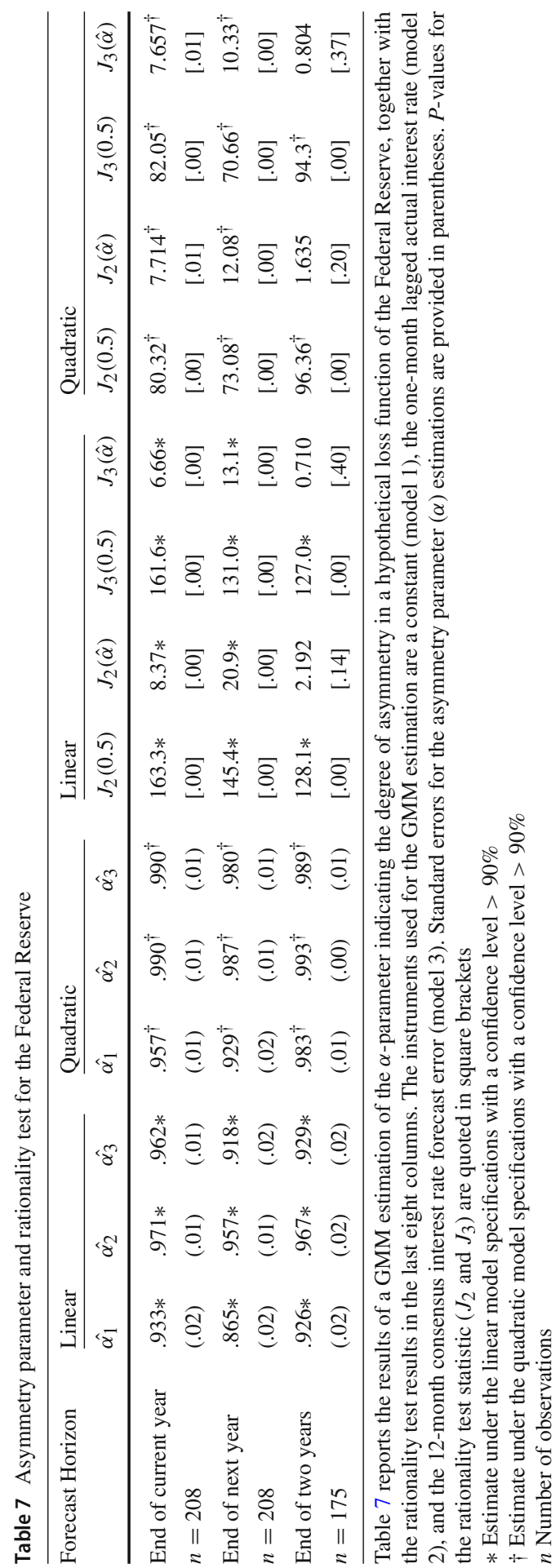


the economic variable on the forecast error. In other words, all information that is considered to influence the forecast is already included therein. Table 4 reports the results of univariate orthogonality tests of the forecast errors for the 3-month forecast horizon and the inflation rate and GDP growth. Against the inflation rate, the Czech Republic, New Zealand, and Norway seem to move toward orthogonality and therefore forecast rationality when switching from a symmetric to an asymmetric loss function. For the test against GDP growth, New Zealand and Sweden exhibit a similar behavior. Therefore, for 5 out of 8 cases, the statistical significance of the F test statistic decreases when switching from symmetric to asymmetric loss functions, making it harder to reject the null hypothesis and therefore indicating movement toward rationality (subject to the implied uncertainty associated with the estimation of the asymmetry parameter). Additionally, Table 8 reports the results of the orthogonality tests for a multivariate specification now including inflation, GDP growth, and unemployment. They represent similar findings. Here, in all four cases statistical significance of the F test statistic decreases, again implying movement toward rationality when allowing for an asymmetric loss function. Figure 6 visualizes this finding showing the $p$-values of the F statistic under a symmetric loss function on the horizontal axis and the respective values under an asymmetric loss function on the vertical axis. The large majority of $p$-value pairs is located above the 45-degree line, indicating an increase in $p$-values when considering $\alpha \neq 0.5$ instead of $\alpha=0.5$. This reflects that the hypothesis of forecast rationality of central bank's interest rate projections is more supported by an asymmetric loss function than a standard symmetric loss function.

\section{Some robustness tests}

\subsection{Rolling window regression}

In order to test for robustness of our results and to possibly identify time-varying or other structural patterns in our $\alpha$-parameter estimates, we begin with conducting a rolling window regression. We apply a window of 25 observations rolling through the respective observation periods for each central bank. The rolling window estimation is conducted for all forecast horizons as set out in Sect. 2, i.e., from one month to 27 months for New Zealand, Sweden, and Norway and from one month to 18 months for the Czech Republic. We apply the original regression model specified in Sect. 4 to each regression window.

Figure 7 provides a graphical illustration of the results of these rolling window regressions for New Zealand forecast horizons of up to 9 months. ${ }^{3}$ Two main observations emerge from this analysis: (1) Estimates of the asymmetry parameter tend to increase with the forecast horizon. This is in line with our previous findings of increasing asymmetry in central banks' loss functions for increasing forecast horizons and therefore confirms robustness across the different rolling windows. (2) The volatility of the $\alpha$-parameter estimates is remarkably low. Besides a weak indication of a time

\footnotetext{
3 For reasons of clear arrangement and parsimony, we refrain from including visual representations for all countries and forecast horizons and central banks; however, these are available upon request.
} 

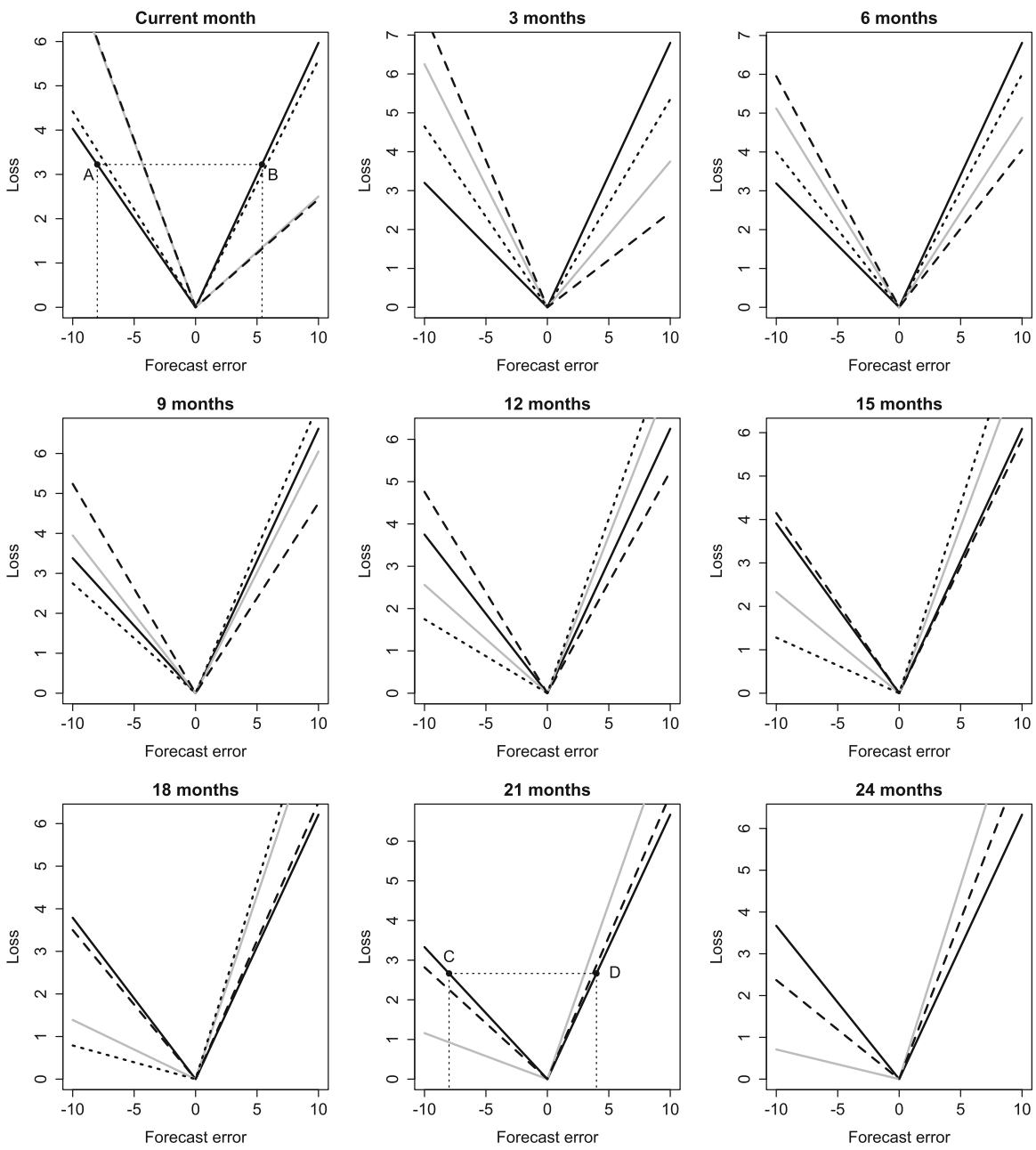

— New Zealand

Sweden

-.- Norway

Czech Republic

Fig. 4 Estimated linear loss functions for different forecast horizons. Note: figure 4 plots the estimated linear loss functions for all four central banks across different forecast horizons. The forecast error is defined as the difference between the actual interest rate and the central bank's projection, i.e., $r_{t+k}-f_{t, t+k}$. While some variance among the four central banks is visible for shorter forecast horizons, a clear trend of moving toward left-sided asymmetry becomes apparent for longer horizons. This implies that underprediction is costlier than overprediction, as discussed in Sect. 5. Due to their different data structure, the USA had to be omitted from this representation

trend with $\alpha$-parameters slightly increasing over time, the estimates overall show only little variation across all regression windows.

The main observations of the rolling window regressions are in line with our previous findings. Moreover, the absence of a structural pattern apart from the identified time trend can be interpreted as robustness of our main empirical analysis. The indication of a time trend for the $\alpha$-parameter, however, is noteworthy. A possible explanation can 


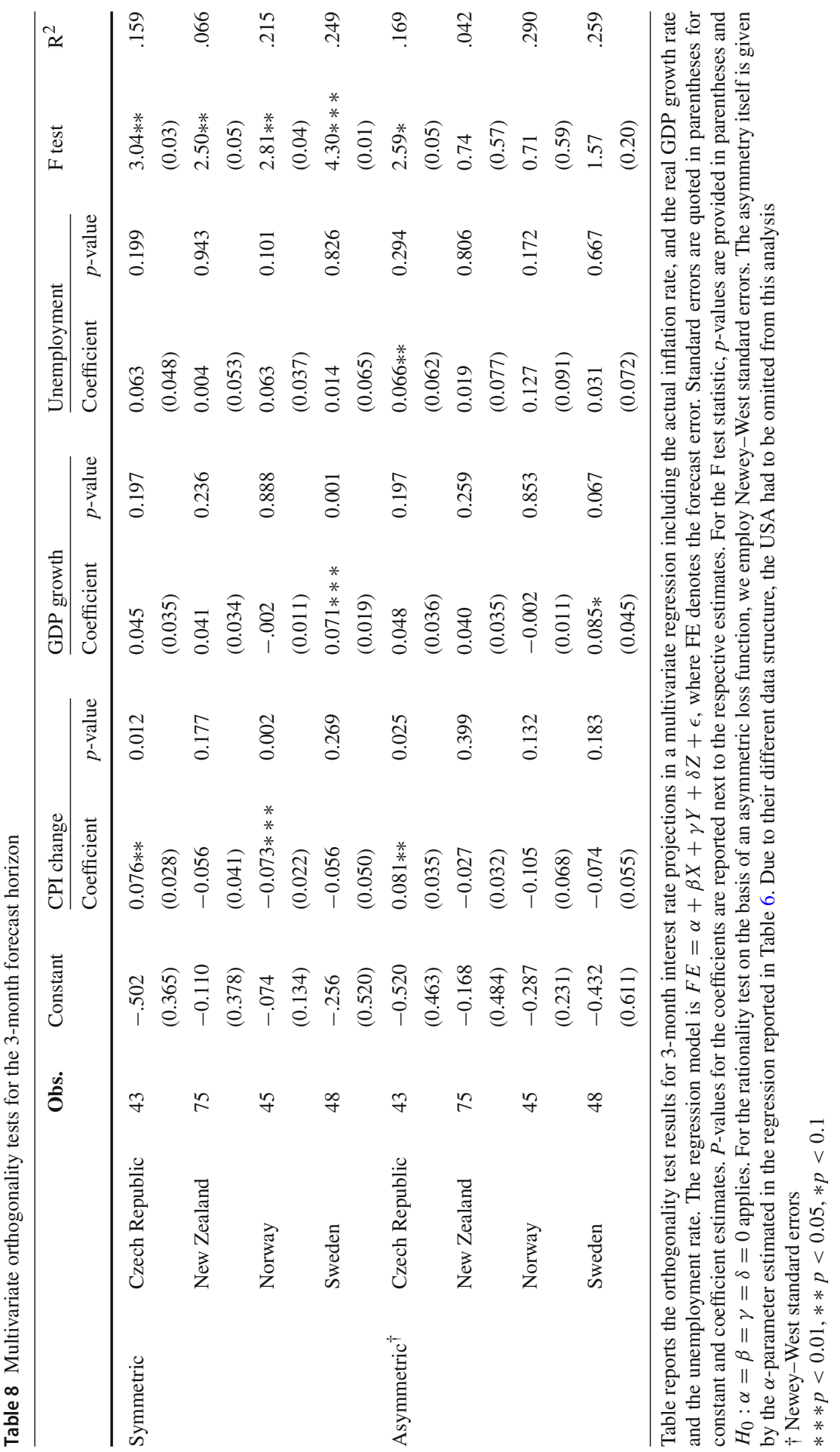



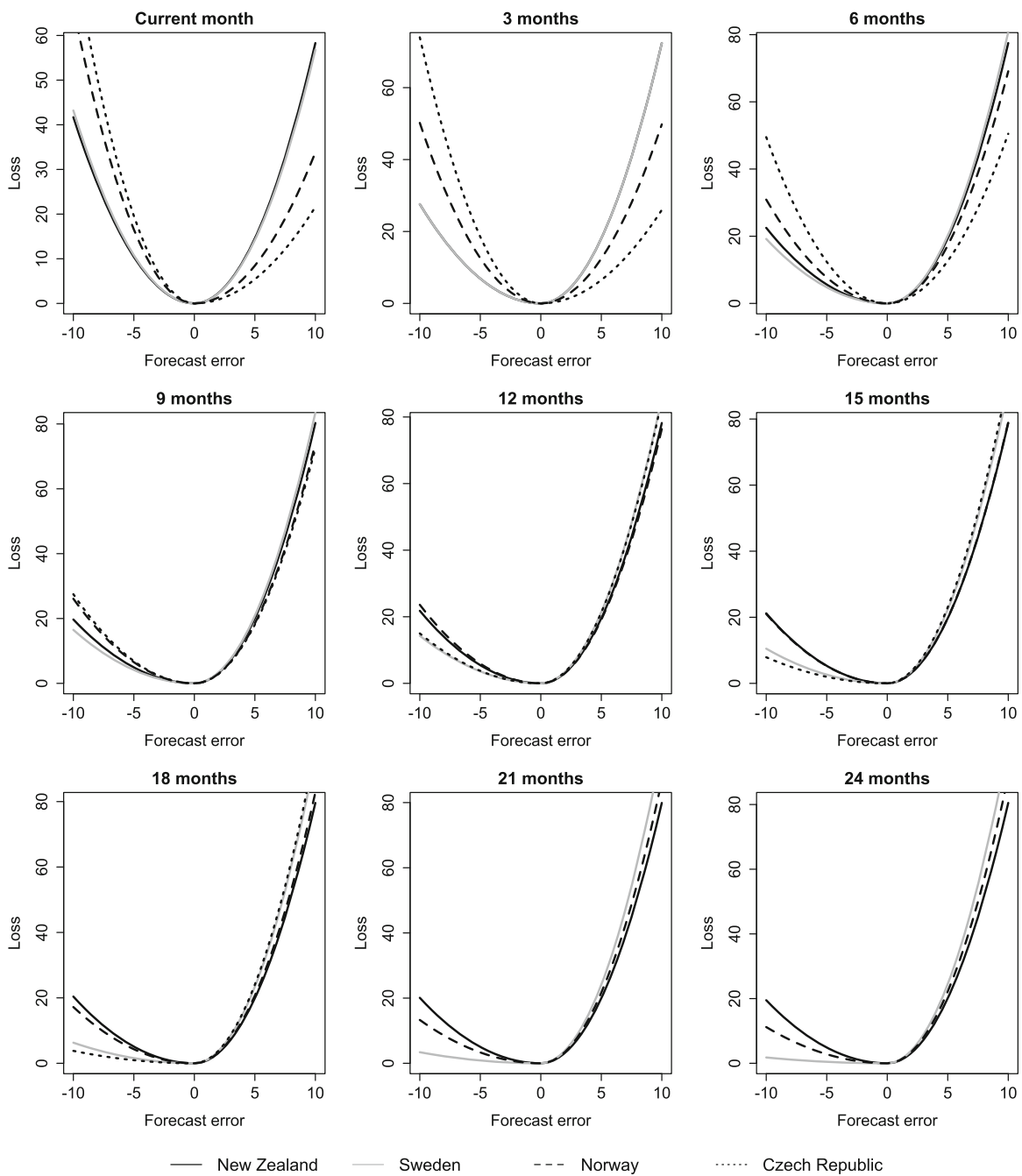

Fig. 5 Estimated quadratic loss functions for different forecast horizons. Note: figure 5 plots the estimated quadratic loss functions for all four central banks across different forecast horizons. The forecast error is defined as the difference between the actual interest rate and the central bank's projection, i.e., $r_{t+k}-$ $f_{t, t+k}$. While some variance among the four central banks is visible for shorter forecast horizons, a clear trend of moving toward left-sided asymmetry becomes apparent for longer horizons. This implies that underprediction is costlier than overprediction, as discussed in Sect. 5. Due to their different data structure, the United States had to be omitted from this representation

be related to the respective time periods included in this analysis. For New Zealand, an entire business cycle is mapped in the data from late 1997 until the end of 2015. By contrast, data for Sweden (Fig. 8) start in Q1 2007 and therefore basically represent the period of the global financial crisis of 2007-2008 with all its ramifications on markets and institutions thereafter. It can be assumed that the exceptional economic circumstances created by the global financial crisis also had an impact on monetary policy and 


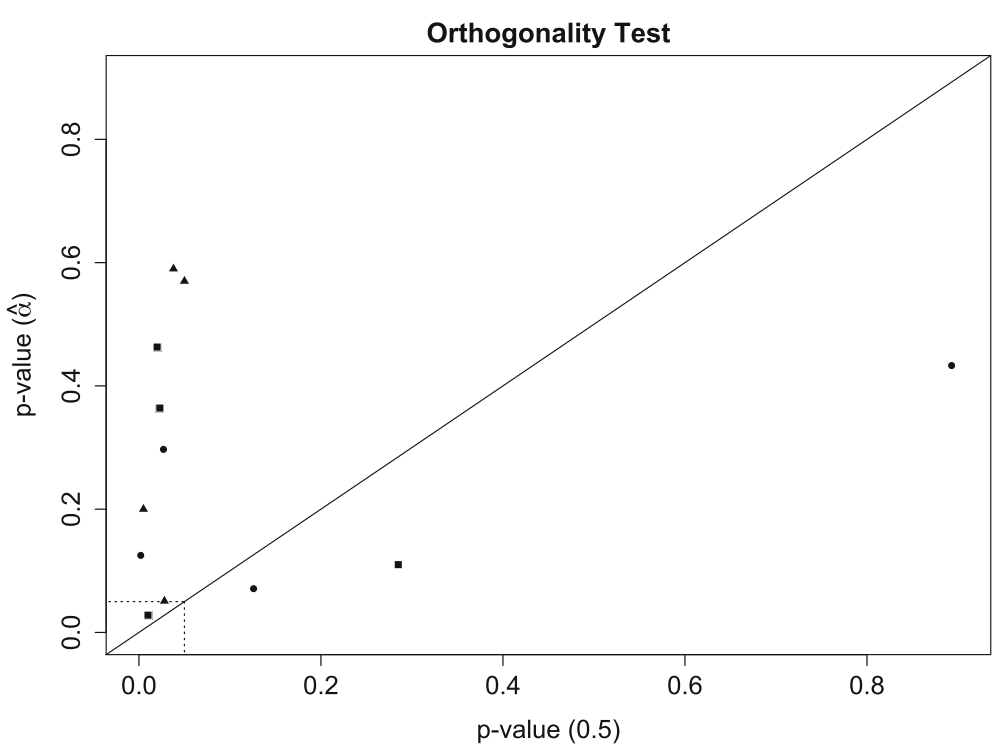

Fig. 6 Orthogonality test scatter plot. Note: figure plots the $p$-values for the F statistic resulting from the orthogonality test regressions. The $p$-value for the $\mathrm{F}$ statistic under a symmetric loss function is plotted on the $x$-axis, whereas the corresponding $p$-value for the same regression under an asymmetric loss function is plotted on the $y$-axis. $P$-values from the orthogonality tests against actual inflation, real GDP growth and a combination of inflation, GDP growth, and unemployment are shown as reported in Tables 4 and 8 . Any marker above the 45-degree line suggests that by moving from a symmetric to an asymmetric loss function, evidence against rationality is weakened. The dotted square at the lower left-hand corner indicates the "zone of statistical significance" at the $95 \%$ confidence level

therefore also on the way, it was communicated. A growing body of related academic literature has scrutinized the changing stance of central bank communication and has consistently found that priorities in central bank communication have shifted (Siklos 2015). The former governor of the Bank of Canada and the current governor of the Bank of England Mark Carney (2009) stipulated that "an effective communications strategy for normal states may prove counterproductive in exuberant states." Siklos (2015) and Vayid (2013) also find that price stability concerns have at least temporarily lost some ground to financial stability matters in central bank communications. Consequently, we can assume that also in the case of the four central banks considered in our study, the different economic conditions created by the global financial crisis led central banks to adjust their communications strategy accordingly. With a higher weight being put on strategic (financial stability) considerations, the inclination toward giving out forecasts that are rational under an asymmetric loss function increases, as briefly pointed out in Sect. 5. Therefore, even though the discussed ideas in Sect. 5 are far from proven, the observation of a time trend in the forecast data revealed by this rolling window regression is at least conformable with the mechanisms discussed. 


\subsection{Pooled regression}

We perform an additional test for robustness by examining whether there is a different forecasting behavior during recession and non-recession periods. A first visual appraisal of forecast errors on the basis of Figure 1 suggests a potential correlation between high interest and low-interest phases with systematic underprediction and overprediction, respectively. In order to identify a possible systematic relationship, we conduct a regression for a sample split, dividing the data set into two parts. Following conventional wisdom, we define a quarter to be in "crisis" when two consecutive quarters of negative real GDP growth have previously occurred and there has not been any positive growth yet. Given the limited number of observations for each central bank and the even more limited number of crisis quarter observations within the data set, we pool all observations across countries before running the regression.

Table 9 reports the resulting $\alpha$-parameter estimates for the data set divided in recession and non-recession periods. The results reveal a considerable difference in $\alpha$ parameter estimates of up to 0.328 between recession and non-recession periods for shorter forecast horizons. For longer forecast horizons, however, the estimates seem to converge and a differentiation between the two period types becomes less meaningful. In line with the arguments brought forward in Sect. 6.1, these findings suggest that there might indeed be reason to believe in a different stance in central bank communication in times of recessions. Moreover, this modified behavior seems to hold especially for communication of macroeconomic indicators in the short term, as indicated by the large difference in $\alpha$ parameter estimates for recession and non-recession periods for the current-month, the 3-month, and the 6-month forecast horizons. Archer (2005) elaborates on the various components included in generating an interest rate projection from the perspective of the RBNZ. Among a number of other factors, he specifically points out ad hoc adjustments to the underlying central bank reaction function based on changing assessments on overall risk and uncertainty. It seems reasonable to assume that during an economic downturn as experienced during the global financial crisis, the assessment of exactly these factors might have changed and led to a corresponding alteration of central banks' forecasting models. In contrast, the convergence of the $\alpha$-parameter estimates for longer forecast horizons regardless of recession or non-recession situations can be interpreted as indicative of long-term targets of central banks which are supposed to be more or less constant and not subject to ad hoc reactions to current circumstances.

In sum, the robustness of our initial results in Sect. 5 is complemented by a differentiated view on the impact that recessions can have on central bank communication in general and interest rate projections in particular.

\section{Conclusion}

Starting from considerations on why it might be rational for central banks to issue biased or inaccurate projections, this paper examines a very recent and innovative central bank communication instrument that has not yet been investigated extensively in the academic literature. Forecast rationality of central bank interest rate projections 

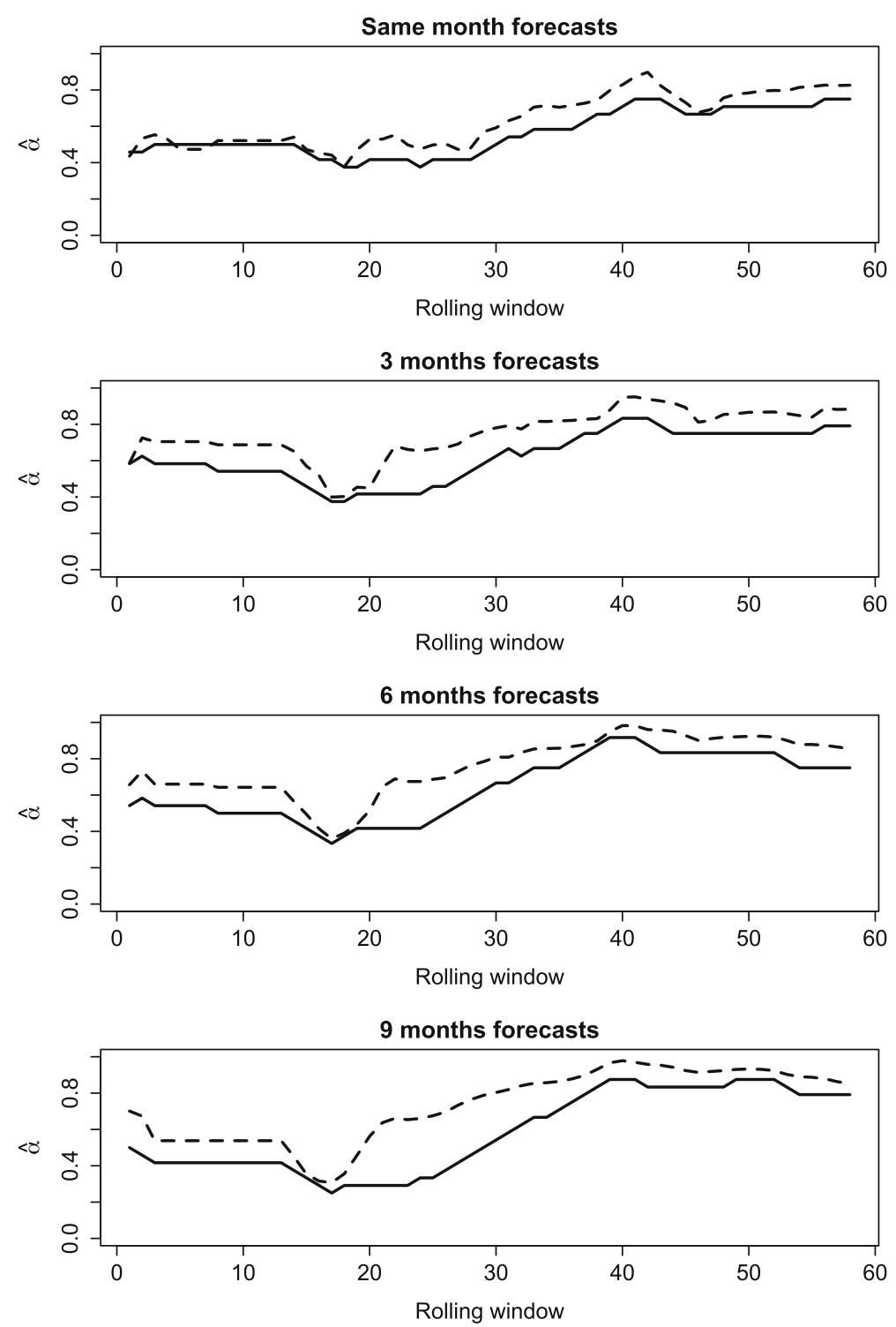

Fig. 7 Rolling window regressions New Zealand. Note: figure plots the estimated $\alpha$-parameters from a rolling window regression for New Zealand for different forecast horizons. The rolling window size is 25 observations, and both linear (solid lines) and quadratic (dotted lines) loss function estimations are presented. The rolling $\alpha$-parameter estimates seem to increase with increasing forecast horizons and also show an upward tendency over time. Further results and interpretations thereof are provided in Sect. 5 


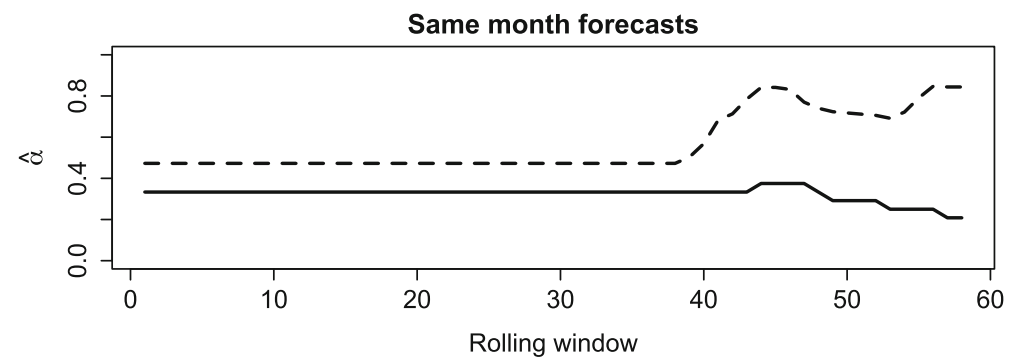

3 months forecasts

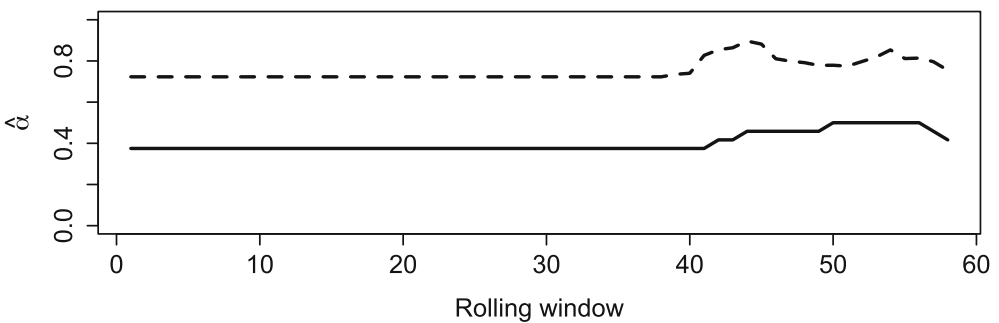

6 months forecasts

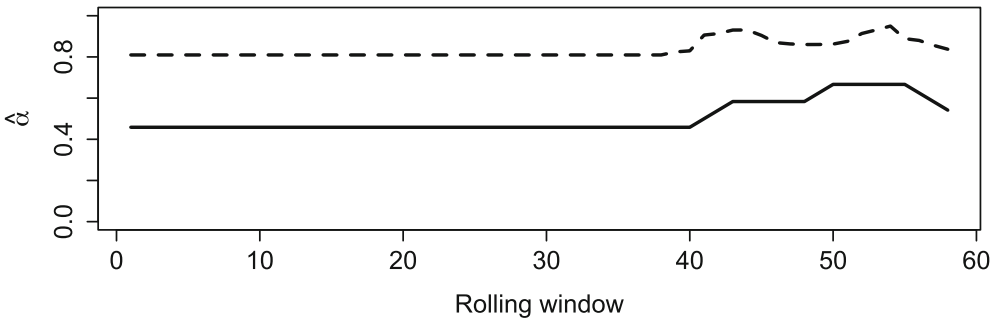

9 months forecasts

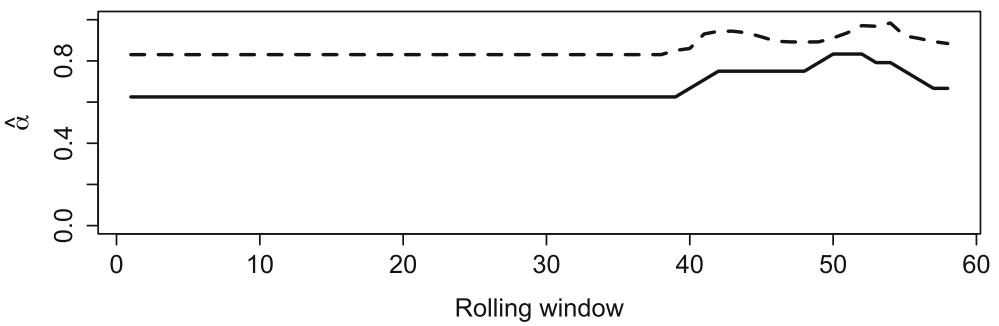

Fig. 8 Rolling window regressions Sweden. Note: figure plots the estimated $\alpha$-parameters from a rolling window regression for Sweden for different forecast horizons. The rolling window size is 25 observations, and both linear (solid lines) and quadratic (dotted lines) loss function estimations are presented. The rolling $\alpha$-parameter estimates seem to increase with increasing forecast horizons and also show an upward tendency over time. Further results and interpretations thereof are provided in Sect. 5 


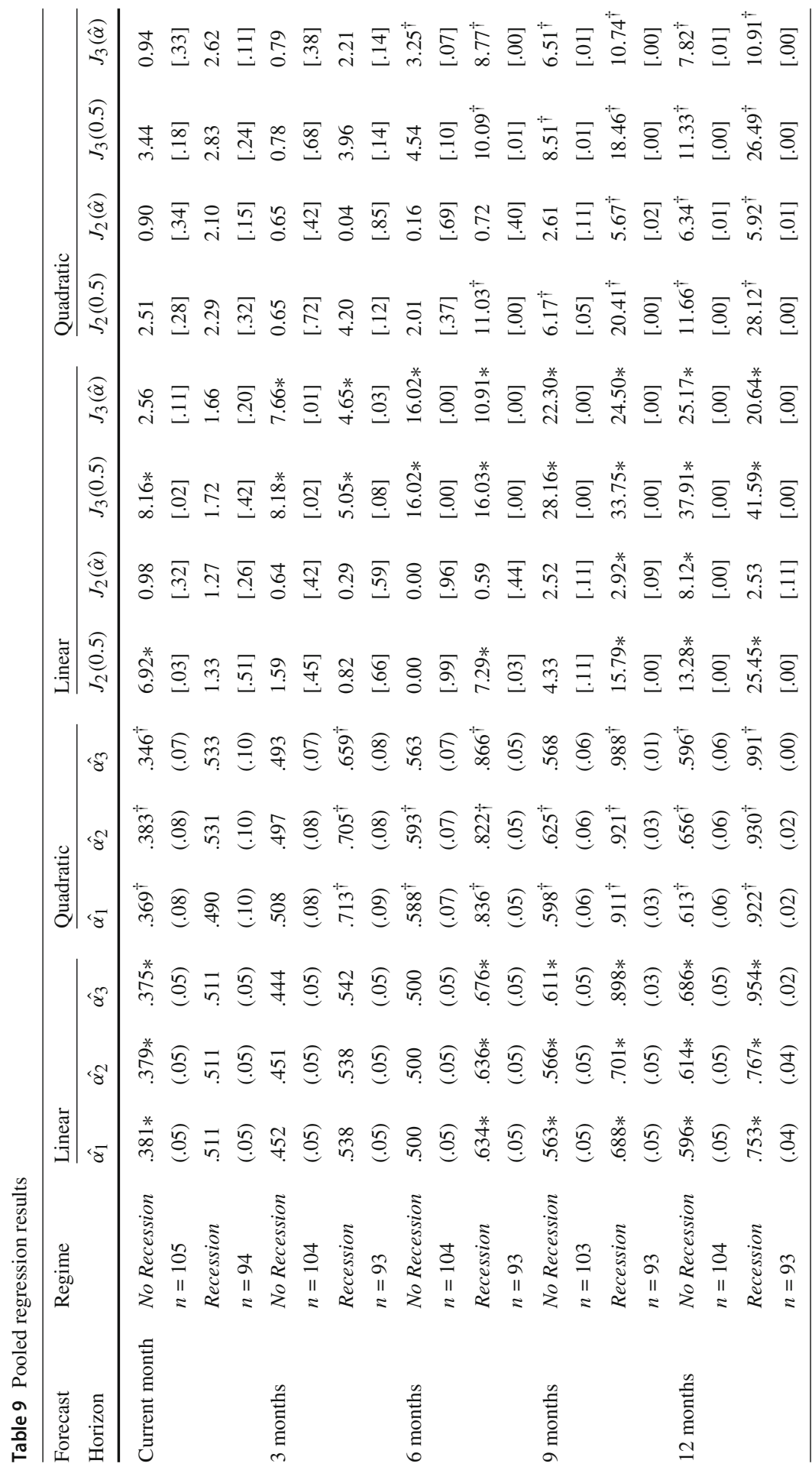




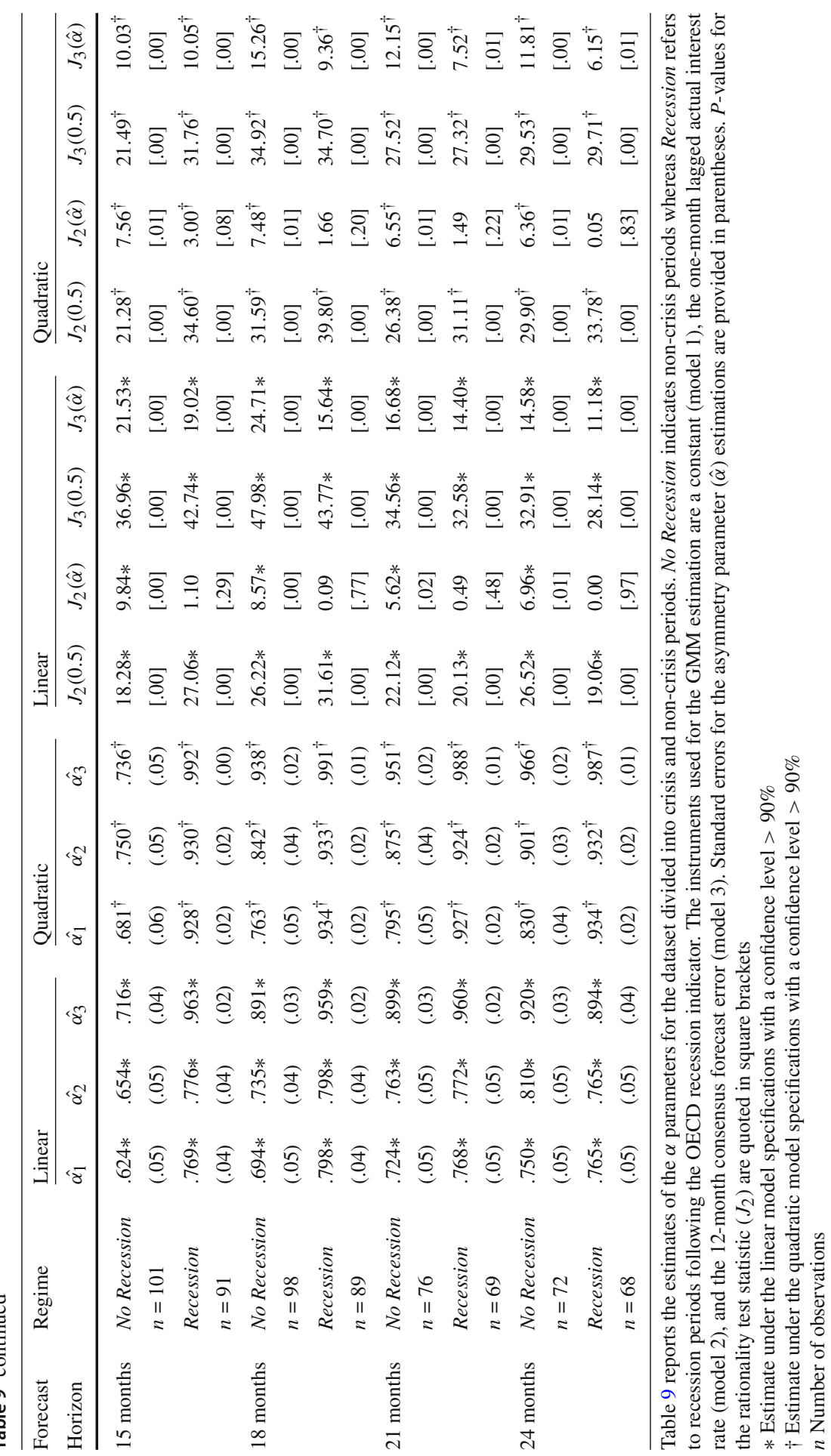


is rejected for most central banks and respective forecast horizons when assuming a symmetric loss function. This, however, needs to be reconsidered when an asymmetric loss function can be assumed. We cannot reject rationality for most interest rate forecast errors when emanating from an asymmetric loss function and even find that with increasing forecast horizons, the asymmetry of the estimated central bank loss functions becomes more pronounced. Particularly with regard to the potential explanations of the detected bias and asymmetry in central banks' interest rate projections, a number of further research questions could be considered. For instance, given that all central banks examined in this paper are under an inflation-targeting regime, an approach to explain the implied asymmetry by nonlinear Taylor rules could look into the question whether interest rate projections are internally consistent with the Taylor principle. Moreover, as mentioned in Sect. 3, the sheer visual representation of actual and projected interest rate paths raises the question whether there is a relationship between business cycle positions and interest rate forecast errors.

What could explain our findings of an asymmetric loss function of central banks? No direct measurement of the motivation of the central banks is possible in this context. Moreover, interest rate projections of central banks are still a relatively new phenomenon. However, a few considerations could at least suggest some answers to this question. In times of very low or even negative interest rates, it could make monetary policy more difficult in the future if the public began to believe that inflation rates will stay very low for a longer period. Then, the public may reduce its aggregate demand and, thereby, prolong the period of economic weakness. To avoid such developments, it could be rational for a central bank to prefer too high interest rate predictions instead of low interest rates forecasts. This would imply that the loss function of the central bank is asymmetric. In addition, this phenomenon should show up in empirical analyses even more strongly if the data include relatively longer periods of very low inflation and interest rates. This is the case in our investigation, because our analysis covers largely periods of low economic activity and very low inflation rates. These considerations could also explain why we find significant results when we include a crisis dummy in our estimation model.

Another reason for the asymmetry that we find in our analysis may be related to the differences in the speed with which central banks adjust their policy rates downwards compared to upwards. There seems to be a tendency of central banks to be relatively quick in stepping in with loose monetary policy in times of a downward pressure on the economy and to be more reluctant to tighten policy stances fast, when price stability risks become more imminent (Weidmann 2017). Many observers have noticed such relatively fast interest-rate reductions in strong economic downturns. In what became known as the "Greenspan put" or subsequently the "Bernanke put," the US Federal Reserve was believed to intervene in financial markets to prevent asset prices to fall too fast (Hall 2011). The studies of Miller et al (2002), Goodhart (2008) and De Nicolo et al (2010) examined this phenomenon. It is usually used as an argument to explain the excessive risk-taking behavior of banks and financial institutions in the run-up to the global financial crisis in 2008, but can also be considered against the background of central banks' interest rate projections (Cecchetti 2007). Assuming that such a mechanism does indeed exist within central banks' objective functions, an asymmetry in adjusting the interest rate might result in a tendency to overpredict 
future interest rate paths when the projections do not anticipate this reluctance at the time of publication of the projection. In other words, a discrepancy between a more or less symmetric forecasting behavior and a subsequent asymmetric interest rate setting behavior may lead to a forecast error different from zero in this scenario. The assumption of a "Greenspan put" might, therefore, be another useful concept to explain the examined overprediction tendency that we have detected in central banks' interest rate projections.

Going forward, central bank interest rate projections are still a relatively new and unexplored field within economic research. Once more data become available, this would allow for more comprehensive studies.

Funding Open Access funding enabled and organized by Projekt DEAL.

\section{Declarations}

Conflict of interest The authors declare that they have no conflict of interest.

Ethical approval This article does not contain any studies with human participants or animals performed by any of the authors.

Code availability All the codes and programs used in the analysis are available on request, and researchers who obtain access to the datasets of the Czech National Bank the Reserve Bank of New Zealand, the Swedish Riksbank, the Norwegian Norges Bank, and the U.S. and the Federal Reserve will be able to replicate all of the findings.

Consent for publication The authors hereby consent to publication of this work in any and all publications by Empirical Economics.

Open Access This article is licensed under a Creative Commons Attribution 4.0 International License, which permits use, sharing, adaptation, distribution and reproduction in any medium or format, as long as you give appropriate credit to the original author(s) and the source, provide a link to the Creative Commons licence, and indicate if changes were made. The images or other third party material in this article are included in the article's Creative Commons licence, unless indicated otherwise in a credit line to the material. If material is not included in the article's Creative Commons licence and your intended use is not permitted by statutory regulation or exceeds the permitted use, you will need to obtain permission directly from the copyright holder. To view a copy of this licence, visit http://creativecommons.org/licenses/by/4.0/.

\section{References}

Archer D (2005) Central bank communication and the publication of interest rate projections. In: A paper for a Sveriges Riksbank conference on inflation targeting

Batchelor R, Dua P (1991) Blue chip rationality tests. J Money Credit Bank 23(4):692. https://doi.org/10. 1353/scp.0.0025

Blinder AS, Ehrmann M, Fratzscher M, De Haan J, Jansen DJ (2008) Central bank communication and monetary policy: A survey of theory and evidence. Journal of Economic Literature 46(4):910-945. https://doi.org/10.1257/jel.46.4.910

Carney M (2009) Some considerations on using monetary policy to stabilize economic activity

Cecchetti SG (2007) Does well-designed monetary policy encourage risk-taking? In: Felton A, Reinhart C (eds) The first global financial crisis of the 21st century, Centre for Economic Policy Research, chap 1 , pp 33-35 
Chortareas G, Jitmaneeroj B, Wood A (2012) Forecast rationality and monetary policy frameworks: evidence from UK interest rate forecasts. J Int Finan Markets Inst Money 22(1):209-231. https://doi.org/10. 1016/j.intfin.2011.09.002

Cohen R, Bonham CS, Abe S (2015) Rationality and heterogeneity of survey forecasts of the yen-dollar exchange rate: a reexamination. In: Handbook of financial econometrics and statistics, Springer, New York, pp 1195-1248. https://doi.org/10.1007/978-1-4614-7750-1_43

Davig T, Leeper EM, Walker TB (2011) Inflation and the fiscal limit. Eur Econ Rev 55(1):31-47. https:// doi.org/10.1016/j.euroecorev.2010.11.005

De Nicolo G, Dell'Ariccia G, Laeven LA, Valencia FV (2010) Monetary policy and bank risk taking. https:// doi.org/10.2139/ssrn.1654582

Detmers GA, Nautz D (2012) The information content of central bank interest rate projections: evidence from New Zealand. Economic Record 88:323-329. https://doi.org/10.1111/j.1475-4932.2012.00813. $\mathrm{X}$

Detmers GA, Nautz D (2013) How stale central bank interest rate projections affect interest rate uncertainty. In: Beiträge zur Jahrestagung des Vereins für Socialpolitik 2013: Wettbewerbspolitik und Regulierung in einer globalen Wirtschaftsordnung - Session: Monetary Policy, http://www.econstor.eu/handle/ $10419 / 79861$

Detmers GA, Nautz D (2014) Stale forward guidance. Econ Lett 124(3):358-361. https://doi.org/10.1016/ j.econlet.2014.06.025

Dovern J (2015) A multivariate analysis of forecast disagreement: confronting models of disagreement with survey data. Eur Econ Rev 80:16-35. https://doi.org/10.1016/j.euroecorev.2015.08.009

Elliott G, Komunjer I, Timmermann A (2005) Estimation and testing of forecast rationality under flexible loss. Rev Econ Stud 72(4):1107-1125

Frenkel M, Rülke JC, Zimmermann L (2012) Do current account forecasters herd? Evidence from the euro area and the G7 countries. Rev Int Econ 20(2):221-236

Frenkel M, Rülke JC, Zimmermann L (2013) Do private sector forecasters chase after IMF or OECD forecasts? J Macroecon 37:217-229. https://doi.org/10.1016/j.jmacro.2013.03.002

Fritsche U, Pierdzioch C, Rülke JC, Stadtmann G (2015) Forecasting the Brazilian real and the Mexican peso: asymmetric loss, forecast rationality, and forecaster herding. Int J Forecast 31(1):130-139. https://doi.org/10.1016/j.ijforecast.2014.08.010

Goodhart CAE (2008) The background to the 2007 financial crisis. IEEP 4(4):331-346. https://doi.org/10. 1007/s10368-007-0098-0

Gosselin P, Lotz A, Wyplosz C (2008) The expected interest rate path: alignment of expectations vs. creative opacity. Int J Central Bank, pp 145-185

Hall P (2011) Is there any evidence of a Greenspan put? Swiss National Bank Working Papers

Holden K, Peel DA (1990) On testing for unbiasedness and efficiency of forecasts. Manchester School Econ Soc Stud 58(2):120-127

Leeper EM, Richter AW, Walker TB (2011) Quantitative effects of fiscal foresight. Am Econ J: Econ Policy 4(2):115-144 https://doi.org/10.1257/pol.4.2.115

Miller M, Weller P, Zhang L (2002) Moral hazard and the US stock market: analysing the 'Greenspan Put'. Econ J 112(478):C171-C186

Muth JF (1961) Rational expectations and the theory of price movements. Econometrica 29(3):315. https:// doi.org/10.2307/1909635

Neuenkirch M (2012) Managing financial market expectations: the role of central bank transparency and central bank communication. Eur J Polit Econ 28(1):1-13. https://doi.org/10.1016/j.ejpoleco.2011. 07.003

Patton AJ, Timmermann A (2012) Forecast rationality tests based on multi-horizon bounds. J Bus Econ Stat 30(1):1-17. https://doi.org/10.1080/07350015.2012.634337

Pierdzioch C, Rülke JC (2014) Central banks' interest rate projections and forecast coordination. N Am J Econ Finance 28:130-137. https://doi.org/10.1016/j.najef.2014.02.006

Pierdzioch C, Rülke JC, Stadtmann G (2015) Central banks' inflation forecasts under asymmetric loss: evidence from four Latin-American countries. Econ Lett 129:66-70. https://doi.org/10.1016/j.econlet. 2015.02.014

Rudebusch GD, Williams JC (2008) Revealing the secrets of the temple the value of Publishing Central Bank Interest Rate Projections. In: NBER working paper no 12638. https://doi.org/10.3386/w12638

Siklos PL (2015) Central Bank Communication After The Crisis - Has Anything Changed? CIGI Commentary 
Vayid I (2013) Central Bank Communications Before, During and After the Crisis : From Open-Market Operations to Open-Mouth Policy. Bank of Canada Working Paper 2013-41

Weidmann J (2017) Current developments in the euro area. Speech by Dr. Jens Weidmann, President of the Deutsche Bundesbank and Chairman of the Board of Directors of the Bank for International Settlements, at the Bank of Slovenia, Ljubljana

Wieland V, Wolters MH (2011) The diversity of forecasts from macroeconomic models of the US economy. Econ Theor 47(2-3):247-292. https://doi.org/10.1007/s00199-010-0549-7

Publisher's Note Springer Nature remains neutral with regard to jurisdictional claims in published maps and institutional affiliations. 